\title{
Spatial and temporal gradients in the rate of dust deposition and aerosol optical thickness in southwestern Iran
}

\author{
Mansour A FOROUSHANI*, Christian OPP, Michael GROLL \\ Department of Geography, Philipps-Universität Marburg, Marburg 35037, Germany
}

\begin{abstract}
The southwestern Iran is one of the regions that are most prone to dust events. The objective of this study is the analysis of the spatial and temporal distributions of dust deposition rate as a key factor for finding the relative impact of the dust. First, the monthly mean aerosol optical thickness (AOT) from Moderate Resolution Imaging Spectroradiometer (MODIS) was analyzed and compared with the dust amount variations from ground deposition rate (GDR), and the results were further used to investigate the spatial and temporal distributions of dust events in southwestern Iran for the period between 2014 and 2015. Moving air mass trajectories, using the Hybrid Single-Particle Lagrangian Integrated Trajectory (HYSPLIT) model, were proven to be a discriminator of their local and regional origin. The results from GDR analysis produced a correlation coefficient between dust event history and deposition rates at dust magnitudes of $>0.93$ that is meaningful at the $95 \%$ confidence level. Furthermore, the deposition rates varied from $3 \mathrm{~g} / \mathrm{m}^{2}$ per month in summer to $10 \mathrm{~g} / \mathrm{m}^{2}$ per month in spring and gave insight into the transport direction of the dust. Within the same time series, AOT correspondences with MODIS on Terra in four aerosol thickness layers (clean, thin, thick, and strong thick) were shown in relation to each other. The deepest mixed layers were observed in spring and summer with a thickness of approximately $3500 \mathrm{~m}$ above ground level in the study area. Investigations of ground-based observations were correlated with the same variations for each aerosol thickness layer from MODIS images and they can be applied to discriminate layers of aeolian dust from layers of other aerosols. Together, dust distribution plots from AOT participated to enhance mass calculations and estimation deposition rates from the thick and strong thick aerosol thickness layers using the results from GDR. Despite all the advances of AOT, under certain circumstances, ground-based observations are better able to represent aerosol conditions over the study area, which were tested in southwestern Iran, even though the low number of observations is a commonly acknowledged drawback of GDR.
\end{abstract}

Keywords: aerosol optical thickness; ground deposition rate; HYSPLIT; dust deposition; Iran

Citation: Mansour A FOROUSHANI, Christian OPP, Michael GROLL. 2021. Spatial and temporal gradients in the rate of dust deposition and aerosol optical thickness in southwestern Iran. Journal of Arid Land, 13(1): 1-22. https://doi.org/10.1007/s40333-020-0079-5

\section{Introduction}

During the last decades, dust event frequency and intensity have increased significantly in the western parts of Iran (Gerivani et al., 2011). Rezaei et al. (2019) analyzed dust studies in Iran

\footnotetext{
*Corresponding author: Mansour A FOROUSHANI (E-mail: mforoushani@gmail.com)

Received 2019-06-25; revised 2020-04-30; accepted 2020-05-28

(C) Xinjiang Institute of Ecology and Geography, Chinese Academy of Sciences, Science Press and Springer-Verlag GmbH Germany, part of Springer Nature 2021
} 
since 2006 and concluded that the southwestern provinces of Iran were characterized by the highest dust deposition rates. Mineral dust aerosols influence the climate system directly by scattering and absorbing radiation (Kaufman and Koren, 2006; Alizadeh et al., 2013), which is associated with alterations in meteorological significance that may change the vertical profiles of temperatures and wind speeds (Alizadeh et al., 2013). During transport, dust particles are continuously removed from the atmosphere by processes of dry and/or wet deposition (Lawrence and Neff, 2009). Several studies have addressed the dust deposition rate (Song et al., 2008; Schaap et al., 2009; Huang et al., 2010; Sorooshian et al., 2011; Balakrishnaiah et al., 2012; Crosbie et al., 2015). However, the most attention was the uncertainties in spatial and temporal distributions, depending on changing patterns of human activities (Neff et al., 2008), different measurement techniques (Sokolik et al., 2001), the concentration of dust in the atmosphere, as well as surface features of the environment of the depositional sites (Tegen and Lacis, 1996). In the long run, the mass deposition rate of dust particles influences air quality (Arimoto et al., 1997; Abdou et al., 2005) and may cause considerable negative health effects (de Longueville et al., 2013; Kharazmi et al., 2018). Having data from the rate are usually used to validate model simulations (Yu et al., 2003) or may provide a useful benchmark. Accordingly, both passive and active sampling techniques can pay off to the lack of information from the rate by ground observations (Taheri et al., 2015).

The most commonly used passive sampling techniques for collecting dust use a nonreactive collection pan, which serves as the depositional surface (Offer and Goossens, 1994; Reheis and Kihl, 1995). However, active sampling is suggested for particle measurements and for air filtration at or near ground level (Prospero et al., 1987). Estimates of deposition from active sampling are subject to the ability to accurately convert atmospheric dust concentrations to rates of deposition (Wesely and Hicks, 2000). Ground-based observations contribute strongly to a better understanding of the processes of aeolian dust transport and the impact of aeolian dust, e.g., in the form of a long-term research project in the Aral Sea Basin from 2003 to 2012 (Groll et al., 2013; Opp et al., 2017). Aerosol optical thickness (AOT) is usually obtained both from ground-based and satellite observations. Many studies have been performed on the high temporal and spectral resolution measurements from the Aerosol Robotics Network (AERONET) in comparison with data from space (Prospero et al., 1987; Rubin et al., 2017). AERONET is a National Aeronautics and Space Administration (NASA) network for monitoring and characterizing atmospheric aerosols by ground-based sun photometer (e.g., Cazacu et al., 2018). It has to be pointed out that due to the regional distribution of the AERONET stations (Binietoglou et al., 2015), the quality and representativeness of the AERONET data, which play an important role in the global dust monitoring (Cesnulyte et al., 2014), are strongly dependent on Light Detection and Ranging (LiDAR) instruments, measurement techniques (Lolli et al., 2018), and subsequent data processing methodologies. Based on these dependencies, AERONET only represents a small area around the monitoring sites and does not provide data with a great spatial coverage (Rubin et al., 2017). While unlikely, AOT predictions from satellites are performed by imaging using a column-integrated measure of the extinction coefficient (Yu et al., 2016) by the quantitative calculation of the effect of the total (anthropogenic plus natural) aerosols. Many algorithms have been applied to NASA's Moderate Resolution Imaging Spectroradiometer (MODIS on Terra and Aqua over the land) to retrieve AOT (Abdou et al., 2005; Kaufman and Koren, 2006). Comparatively, the standard collection product from MODIS has been used in many aerosol studies (Golitsyn and Gillette, 1993; Sorooshian et al., 2011). Experiences from aerosol patterns represented the seasonal climatology of AOT over the Indian subcontinent (Maiti and Prasad, 2016). Included are the long-term AOT variation in eastern China from 2001 to 2010 (Kim et al., 2014) and an application in northern China using the Multi-angle Imaging SpectroRadiometer (MISR) over a three year period (Qi et al., 2013). In addition, observed concentration, deposition, and AOT measured by satellite instruments can be used to estimate the overall source location and temporal evolution of the transported material (Bieringer et al., 2017; Hutchinson et al., 2017). Several studies have attempted to make such estimations, using a number of different approaches from model comparisons to field measurements (Chai et al., 2015; Ngan et al., 2015; Stein et al., 2015). In 
order to demonstrate the aerosol movement, researchers used a Hybrid Single Particle Lagrangian Integrated Trajectory (HYSPLIT) model (Wang et al., 2011; Chen et al., 2013; Ashrafi et al., 2014) for the trajectory analysis and its back trajectory at different heights to investigate the origin of particles prior to their arrival at a given place (Cazacu et al., 2018). To allow the discrimination of separate layers of aeolian dust from layers of other aerosols (Yasui et al., 2005), HYSPLIT facilitates the development of backward and forward trajectories (Draxler and Hess, 1998) and computes complex dispersions at various altitudes with a resolution of $500 \mathrm{~m} \times 500 \mathrm{~m}$ and a horizontal grid of $1.5^{\circ} \times 1.5^{\circ}$ (Ashrafi et al., 2014).

The ground deposition rate (GDR) can determine key points of dust activity to identify the general directions and areas of emission, an essential prerequisite for a better understanding of dust processes. Therefore, this study is focused primarily on direct measurements of dust deposition, which is made by passive sampling techniques. As mentioned before, many studies have been done to evaluate dust deposition rates using different techniques in Iran and in other countries (e.g., Sorooshian et al., 2011; Ashrafi et al., 2014). However, the GDR in southwestern Iran has not been investigated very well. Providing an assessment of dust deposition rates against the relevant criteria such as wind, rain, and temperature, evaluating the spatial distribution of the dust deposition, and observing the potential relationship between total dust distribution and AOT will address the following research questions: (1) What is the level of dust deposition that is representative for the study area (southwestern Iran)? (2) What spatial variations in dust deposition can be identified? (3) How do the measured dust deposition rates compare to AOT in the period from March 2014 to March 2015?

The results from ground-based observations together, along with analyzed data from AOT, were compared for a more detailed monthly dust event over the study area. AOT data were analyzed to understand the spatial and temporal patterns of the points with the same variation and intensity to GDR for the period of 2014-2015. The corresponding points were used in HYSPLIT for the model output.

\section{Study area}

Iran has a complex plain and hilly terrain and is located between the southern coast of the Caspian Sea and the northern coast of the Persian Gulf and the sea of Oman. The study area is located between the west side of the Zagros Mountain Range and neighboring areas to the international border with Iraq to the west (Fig. 1). In the study area, the sampling facilities and equipment that correspond to the gauge sites from the north to the south are assigned to G01-G10. The altitude ranges from sea level in the southern part to $900 \mathrm{~m}$ a.s.l. in the north and to $4000 \mathrm{~m}$ a.s.l. in the east. Near the coast, the climate is dry and humid (G09, G10), while dry desert and hot semi-desert climate extend from G01 to G04 and from G06 to G08, with a Mediterranean climate in the northeast which is next and close to the mountain range.

The minimum and maximum values of mean precipitation at gauge sites G10 and G06 were given as 7 and $26 \mathrm{~mm}$, respectively (Iran Meteorological Organization, 2014; IRMO, 2016). However, monthly precipitation was notably below the average at G01 $(8 \mathrm{~mm})$. It is likely that the precipitation values at G07 $(9 \mathrm{~mm}), \mathrm{G} 08(13 \mathrm{~mm})$, and G09 $(12 \mathrm{~mm})$ can be classified at the same level below the median value of $15 \mathrm{~mm}$, thereby extending into G10. In contrast, the precipitation at gauge sites G03, G04, G05, and G06, indicated a value of $19 \mathrm{~mm}$, which was above average $(15 \mathrm{~mm})$. Ambient monthly temperatures were observed during nearly the entire fieldwork period for maximum and minimum values. A long period of maximum warm points fluctuated between $29^{\circ} \mathrm{C}$ and $39^{\circ} \mathrm{C}$ in the area of G01, at G02 in the west, and also at G07, G08, G09, and G10 in the southwest, with a distinct magnitude of $29^{\circ} \mathrm{C}$ for $\mathrm{G} 05$. The annual minimum temperature at the deposition sites was also warmer than average with the exception of G05, which experienced a minimum value of $2^{\circ} \mathrm{C}$.

Wind speed direction data covering mainly the period from March 2014 to March 2015 were indicated from cities where the gauge sites are located. Winds from the north and west blew up to $4 \mathrm{~m} / \mathrm{s}$ at G01, G02, G03, and G04. The maximum north and westward wind speeds of $3 \mathrm{and} 4 \mathrm{~m} / \mathrm{s}$ 
were detected at G09 and G10, respectively. However, the southeastward wind was projected with the speeds of 3 and $2 \mathrm{~m} / \mathrm{s}$ at G07 and G08, respectively; while at G05, the higher wind speed was recorded only up to $2 \mathrm{~m} / \mathrm{s}$.
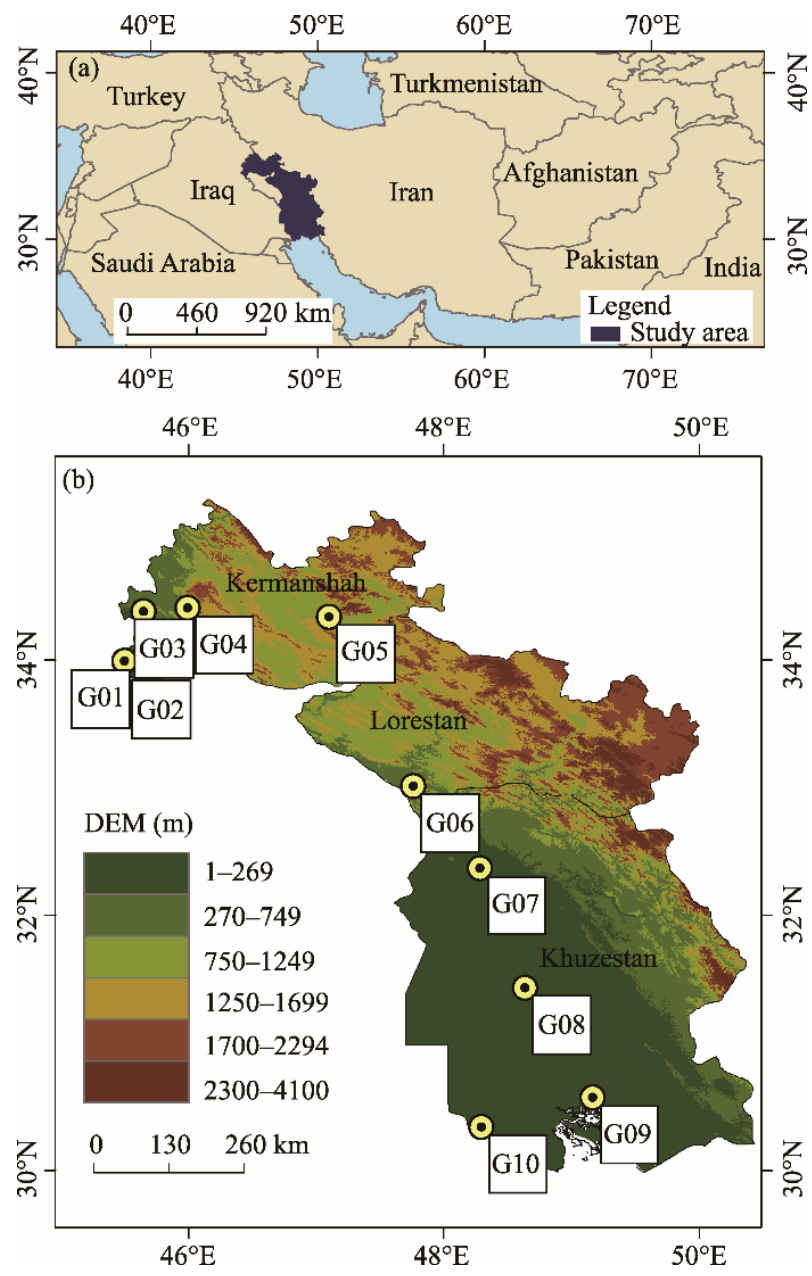

Fig. 1 Location of the study area (a) and the distribution of ground dust collectors (G01-G10) and altitudes in the study area (b). DEMs (digital elevation models) are globally affordable and have approximately $1 \mathrm{~km}$ resolution from GTOPO30 (a global DEM with a horizontal grid spacing of 30 arc seconds) through the USGS (U.S. Geological Survey) Explorer dataset GTOPO30 (ASTER Science Team, 2001).

\section{Methods and data}

Comparing the results of monthly mean AOT from MODIS and data from weighting GDR using enhancement algorithms were used to investigate the spatial and temporal distributions of dust events in the southwestern Iran for the period between 2014 and 2015. Time-space consistency between AOT and GDR were defined. The results by agreement with model output of HYSPLIT were taken into further calculation to improve estimation of the dust deposition rate from the separate thickness layers.

\subsection{Testing method}

For the GDR method, a correlation function in high magnitude and $P$-value $<0.05$ from mass deposition rate and dust event history in accordance to synoptic report, when visibility has been reduced below $1000 \mathrm{~m}$, were suggested. Visibility data were obtained from the Iran Meteorological Organization (IRMO, 2016) to compare with AOT values. Cases with inconsistent values have been removed from further calculation. For the second sort of dataset from the 
MODIS, preliminary qualitative comparisons were taken for all cases selected from the aforementioned process, and AOT values were calculated and justified with NASA's MISR. MISR images were captured from Giovanni MISR $555 \mathrm{~nm}$ and applied with a spatial resolution of $0.5^{\circ}$. The analysis of the time series revealed a potentially promising correlation between the derived thickness layers from AOT and actual deposition rate data from ground surveying. The interpretation of fluctuated values of AOT, derived from the MODIS on Terra measurements, depicted variation of the thickness layers to discriminate separating layers of aeolian dust with the same variation and high correlation relationship from aerosols background.

\subsection{Data from ground surveying}

The dust deposition rate was measured by positioning 20 dust deposit gauges at 10 gauge sites to improve the observation and surveillance quality (Table 1). Both gravimetric and directional dust samplers (20 in total) have been deployed to satisfy requirements of ASTM D1356-05 (IHS under license with ASTM, 2010) and have operated since 2014. As illustrated in Table 1, dust samples were collected monthly for gauges installed at 10 gauge sites for 12 months from March 2014 to March 2015.

Table 1 Location of dust samplers in the study area

\begin{tabular}{ccccccc}
\hline No. & $\begin{array}{c}\text { Gauge site } \\
\text { number }\end{array}$ & $\begin{array}{c}\text { Latitude } \\
\left({ }^{\circ} \mathrm{N}\right)\end{array}$ & $\begin{array}{c}\text { Longitude } \\
\left({ }^{\circ} \mathrm{E}\right)\end{array}$ & Environment & $\begin{array}{c}\text { Altitude } \\
(\mathrm{m} \text { a.s.1. })\end{array}$ & $\begin{array}{c}\text { Total distance } \\
(\mathrm{km})\end{array}$ \\
\hline 1 & G01 & 34.000553 & 45.497595 & Light industry and semi-desert & 144 & 0 \\
2 & G02 & 34.007182 & 45.499075 & Light industry and semi-desert & 184 & 1 \\
3 & G03 & 34.393584 & 45.648174 & Semi-desert & 394 & 52 \\
4 & G04 & 34.423028 & 45.993753 & Road traffic load & 910 & 113 \\
5 & G05 & 34.353365 & 47.101335 & Census densely occupied & 1304 & 245 \\
6 & G06 & 33.024976 & 47.759393 & Light industry and village & 581 & 632 \\
7 & G07 & 32.380038 & 48.282664 & Light industry and village & 109 & 733 \\
8 & G08 & 31.445194 & 48.632398 & Light industry and village & 25 & 860 \\
9 & G09 & 30.584651 & 49.163632 & Census occupied & 6 & 991 \\
10 & G10 & 30.352411 & 48.292293 & Road traffic load & 2 & 1091 \\
\hline
\end{tabular}

Note: Dust samplers were classified with respect to the environment land cover dominance (Levy et al., 2013).

After each monthly sampling and after every exposure period, dust samples were removed from the sites and sent to the Air Research Laboratory of the University of Marburg, Germany for further analysis (Fig. 2). Copies of these laboratory reports are presented in the sections containing the results and discussion. We classified the collected data into dust events based on the total suspended particulate matter (TSP) in combination with the visibility and wind speed (Iran Meteorological Organization, 2014; IRMO, 2016).

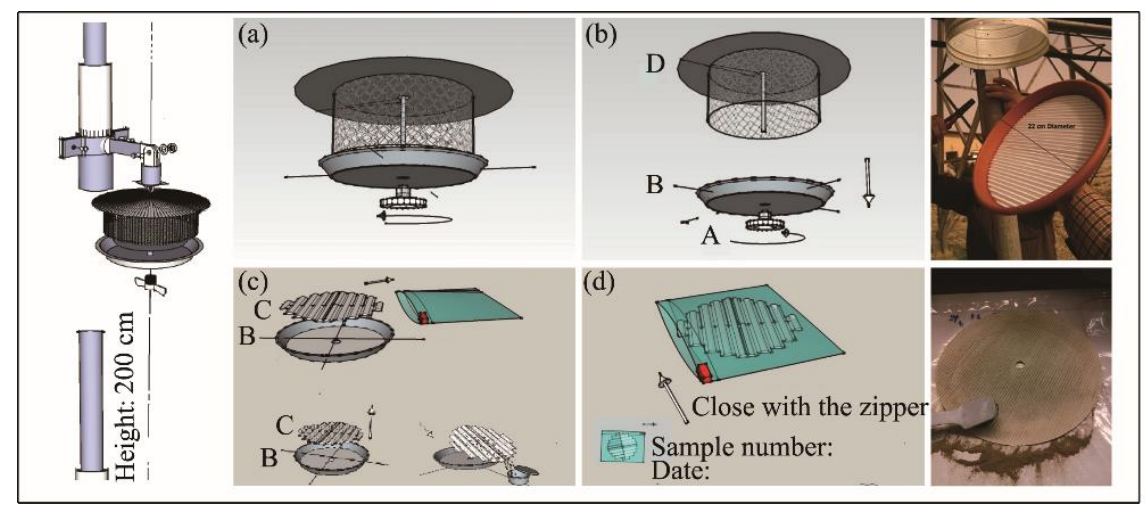

Fig. 2 Construction and collecting of samples from sampling points. Sampling process is represented in (a), (b), (c), and (d). Sampling begins from removing sampling plate (A and B) followed by replace filter, and packing samples with caution (C and D). 
Since this study covers a vast area in the southwestern Iran and encompasses a range of conditions associated with topography and meteorology, the study area was categorized into three sections. Specifically, we assigned G01, G02, G03, and G04 to the first section (Section A), G05 and G06 to the second section (Section B), and G07, G08, G09, and G10 to the last and third section (Section C).

\subsection{Aerosol optical thickness}

Twelve months of records of AOT at $550 \mathrm{~nm}$ were obtained from the MODIS instrument onboard the NASA Terra satellite since March 2014. Aside from high spatial resolution, Terra level 3 is providing data ranging from $250 \mathrm{~m}$ to $1 \mathrm{~km}$, allowing for almost daily world coverage collection from MODIS (Q1: quality controlled AOT) aerosol repository.

MODIS AOT data were collected over a larger area of $30^{\circ}-50^{\circ} \mathrm{N}$ and $35^{\circ}-45^{\circ} \mathrm{E}$, as well as regional dust loading points. Data with a very good quality were flagged to generate AOT statistics over the study area with $0.5^{\circ}-1.0^{\circ}$ resolution (at $550 \mathrm{~nm}$ over dark targets for land only have been selected) (Table 2). We calculated the maximum, minimum, mean, and standard deviation of AOT values from all pixels which already had been changed to point features and fall within each class, and analyzed the differences between the mean values in different classes. After converting the results to points, the Kriging interpolation method was applied to the pixel values (Dindaroğlu, 2014; Franklin et al., 2018). Kriging interpolation method is a geostatistical approach used to calculate weights for measured points and to derive predicted values for unmeasured locations. Ultimately, the Iterative Self-Organizing Data Analysis Technique (ISODATA) classification was applied to AOT (at $550 \mathrm{~nm}$ ) of the monthly images for the period between 2014 and 2015.

Table 2 Titles of Giovanni online data systems developed and maintained by National Aeronautics and Space Administration (NASA) Goddard Earth Sciences Data and Information Services Center (GES DISC)

\begin{tabular}{lcccc}
\hline \multicolumn{1}{c}{ Dataset sensor, satellite, and bandwidth } & Platform & Availability & Spatial resolution & Temporal resolution \\
\hline $\begin{array}{l}\text { MOD08_M3 v6.1 at 550 nm dark target, for } \\
\text { land only }\end{array}$ & Terra level 3 & $\begin{array}{c}1 \text { Mar 2000 } \\
1 \text { Feb 2000 }\end{array}$ & $\begin{array}{c}0.1^{\circ} \times 0.1^{\circ} \\
(10 \mathrm{~km} \times 10 \mathrm{~km})\end{array}$ & $\begin{array}{c}\text { Daily, 8 d, and } \\
\text { monthly }\end{array}$ \\
$\begin{array}{l}\text { MOD08_M3 v6.1 at 550 nm deep blue aerosol, } \\
\text { for land only }\end{array}$ & Terra level 3 & Giovanni & $1.0^{\circ} \times 1.0^{\circ}$ & Monthly \\
$\begin{array}{l}\text { MOD08_M3 v6.1 at 550 nm deep blue aerosol, } \\
\text { for land and ocean }\end{array}$ & Terra level 3 & Giovanni & $1.0^{\circ} \times 1.0^{\circ}$ & Monthly \\
$\begin{array}{l}\text { MIL3MAE v4, MISR aerosol optical depth 555 } \\
\text { nm }\end{array}$ & Terra & $\begin{array}{c}1 \text { Mar 2000 } \\
\text { Giovanni }\end{array}$ & $0.5^{\circ} \times 0.5^{\circ}$ & Daily and monthly \\
\hline
\end{tabular}

Note: Dark target has separate algorithms for land and ocean. Deep blue in the MODIS aerosol products is a land retrieval only. Land algorithm method works best over dark vegetated targets and does not work over bright land surfaces.

\subsection{HYSPLIT model trajectory review}

The NOAA Air Research Library provided the tools (https://ready.arl.noaa.gov/hypub-bin/trajtype.pl) for calculating forward or backward trajectories and specifying the start/end point location as well as the period over which to calculate the trajectories. Surface wind observations and air above ground based level trajectories were included using the local wind profile (Stein et al., 2015; Rolph et al., 2017). We applied backward trajectories model output (NOAA HYSPLIT) over three sections (A, B, and $\mathrm{C}$ ) to obtain the direction and updraft located above ground-based level relatively and to reveal the influence of direct or indirect effects of the dust transport on deposition rates. During the steady state results from the dust evidence from both AOT and GDR, each section has its own longitude and latitude direction and three trajectories were respectively simulated from 100, 500, and $1000 \mathrm{~m}$ for above ground-based level backward to $90 \mathrm{~h}$ before reaching the section points $(\mathrm{A}, \mathrm{B}$, and $\mathrm{C})$.

\section{Results analysis and validation}

We obtained monthly GDR data using statistical calculations for approximately 12 months since March 2014, and downloaded MODIS monthly AOT onboard Terra satellite (MOD08_M3) data according to the study area coordinate system. The pixel values of each image were rebuilt and 
refined. Correlation coefficients were used to find relationships between dust event frequencies and GDR for selecting justified collections. The MODIS provided data according to decimal degrees; accordingly, all the ground station coordinates were converted to decimal degrees. The zonal statistic trend results from AOT justified collection from GDR run into HYSPLIT model, which provided backward trajectory data from dust transport directions. It should be noted that we discussed variations in both GDR and AOT in the discussion section, based on model output.

\subsection{Ground monitoring results}

Table 3 represents dust event frequency, in concert with the dust deposition rate. In the given time, the total dust event frequency values were 0 and 1 time at G05 and G06, while 19, 17, 16, and 12 times at G01, G02, G10, and G09, respectively. However, the total dust event frequency values of 8 times were recorded at sites G08 and G03. The same magnitudes were also found at sites G01 and G02 during March, April, and May of 2014. The average dust deposition rates ranged from 0.3 (G04-G06) to $1.2 \mathrm{mg} / \mathrm{cm}^{2}$ (G01), equaling monthly field deposition rates of $3-12 \mathrm{~g} / \mathrm{m}^{2}$ per month; while the maximum values were between 12 and $30 \mathrm{~g} / \mathrm{m}^{2}$ per month, recorded in summer of 2014 and spring of 2015. Correlation magnitudes of $0.35,0.49$, and 0.69 were indicated for the deposition rates at sites G05, G02, and G08, respectively. Given these points, the ground deposition rates (GDRs) were observed in March, April, and May of 2014 (G01, G02, and G03, respectively) with significant $P$-value $<0.04$ and correlation coefficients ranging from $73 \%$ to 96\%. Similarly, with significant $P$-value $<0.05$, high correlation coefficients between $69 \%$ and 93\% were observed in January and February of 2015 (G10, G09, G08, and G07). Interestingly, the high correlation coefficients with statistically significant differences would be wishful to make remarkable time of evidence into discussion.

Table 3 Description of dust deposition rates and dust event frequency

\begin{tabular}{|c|c|c|c|c|c|c|c|c|c|c|c|c|c|}
\hline \multicolumn{2}{|c|}{ Collection time } & \multicolumn{11}{|c|}{ Dust deposition rate $\left(\mathrm{mg} / \mathrm{cm}^{2}\right)$} & \multirow{2}{*}{$\begin{array}{l}\text { Gauge site } \\
\text { (M.W.) }\end{array}$} \\
\hline Year & Month & G10 & G09 & G08 & G07 & G06 & G05 & G04 & G03 & G02 & G01 & Total & \\
\hline \multirow[t]{10}{*}{2014} & Mar & 1.00 & 0.60 & 0.70 & 0.20 & 0.20 & 0.50 & 0.20 & 0.80 & 0.80 & 0.60 & 5.60 & G10 \\
\hline & Apr & 0.80 & 0.90 & 0.50 & 1.00 & 0.20 & 0.20 & 2.00 & 0.50 & 2.00 & 2.60 & 10.70 & G01 \\
\hline & May & 0.20 & 0.50 & 0.20 & 0.50 & 0.10 & 0.30 & 3.00 & 0.30 & 0.50 & 1.00 & 6.60 & G04 \\
\hline & Jun & 1.00 & 1.00 & 0.60 & 0.50 & 0.20 & 1.00 & 0.20 & 0.80 & 0.80 & 1.50 & 7.60 & G01 \\
\hline & Jul & 0.90 & 1.20 & 1.90 & 0.60 & 0.30 & 0.90 & 0.20 & 0.80 & 0.50 & 0.80 & 8.10 & G08 \\
\hline & Aug & 2.10 & 1.80 & 2.00 & 0.30 & 0.60 & 2.00 & 0.00 & 0.90 & 1.00 & 1.50 & 12.20 & G10 \\
\hline & Sep & 0.90 & 0.90 & 0.60 & 0.20 & 0.00 & 1.00 & 0.50 & 0.90 & 1.50 & 1.50 & 8.00 & G01 \\
\hline & Oct & 0.30 & 0.30 & 0.30 & 0.20 & 0.00 & 0.10 & 0.20 & 0.20 & 0.60 & 0.90 & 3.10 & G01 \\
\hline & Nov & 0.20 & 0.50 & 0.20 & 0.20 & 1.00 & 0.10 & 0.20 & 0.20 & 0.90 & 2.00 & 5.50 & G01 \\
\hline & Dec & 1.00 & 0.30 & 0.30 & 0.90 & 0.20 & 0.20 & 0.20 & 0.10 & 0.20 & 1.50 & 4.90 & G01 \\
\hline \multirow[t]{5}{*}{2015} & Jan & 3.10 & 2.50 & 2.00 & 2.50 & 0.30 & 0.20 & 0.60 & 0.80 & 1.00 & 1.80 & 14.80 & G10 \\
\hline & Feb & 1.10 & 1.50 & 0.80 & 1.70 & 0.10 & 0.20 & 0.20 & 0.60 & 0.40 & 0.50 & 7.10 & G07 \\
\hline & Mar & 2.10 & 0.70 & 0.90 & 1.00 & 0.20 & 0.60 & 0.50 & 0.40 & 0.30 & 0.80 & 7.50 & G07 \\
\hline & & \multicolumn{11}{|c|}{ Dust deposition rate and dust event frequency } & \\
\hline & & G10 & G09 & G08 & G07 & G06 & G05 & G04 & G03 & G02 & G01 & Total & \\
\hline \multirow{2}{*}{\multicolumn{2}{|c|}{$\begin{array}{l}\text { Dust deposition rate in total } \\
\left(\mathrm{mg} / \mathrm{cm}^{2}\right)\end{array}$}} & 14.70 & 12.70 & 11.00 & 9.8 & 3.40 & 7.30 & 8.00 & 7.30 & 10.50 & 17.00 & 101.70 & \\
\hline & & $\begin{array}{c}\text { Jan } \\
2015\end{array}$ & $\begin{array}{c}\text { Jan } \\
2015\end{array}$ & $\begin{array}{c}\text { Jan } \\
2015\end{array}$ & $\begin{array}{c}\text { Jan } \\
2015\end{array}$ & $\begin{array}{l}\text { Nov } \\
2014\end{array}$ & $\begin{array}{l}\text { Aug } \\
2014\end{array}$ & $\begin{array}{l}\text { May } \\
2014\end{array}$ & $\begin{array}{c}\text { Sep } \\
2014\end{array}$ & $\begin{array}{c}\text { Apr } \\
2014\end{array}$ & $\begin{array}{c}\text { Apr } \\
2014\end{array}$ & & \\
\hline \multirow{3}{*}{\multicolumn{2}{|c|}{ Dust event frequency (times) }} & 16 & 12 & 8 & 7 & 0 & 1 & 2 & 8 & 17 & 19 & & \\
\hline & & \multicolumn{11}{|c|}{ Statistics } & \\
\hline & & G10 & G09 & G08 & G07 & G06 & G05 & G04 & G03 & G02 & G01 & & \\
\hline \multirow{2}{*}{\multicolumn{2}{|c|}{$\begin{array}{l}\text { Correlation coefficient } \\
\qquad P \text {-value }\end{array}$}} & $74 \%$ & $93 \%$ & $69 \%$ & $85 \%$ & - & $35 \%$ & $73 \%$ & $81 \%$ & $49 \%$ & $96 \%$ & & \\
\hline & & 0.05 & 0.05 & 0.05 & 0.05 & NA & NA & 0.05 & 0.05 & 0.05 & 0.05 & & \\
\hline
\end{tabular}

Note: -, no data; NA, not significant; M.W., maximum witness, which means that the site number is witnessed the maximum deposition rates. 


\subsection{AOT results}

Mapping pixel values of the study area were calculated and classified into four different layers of aerosol thickness, including clean, thin, thick, and strong thick (Figs. 3-5). Monthly variations and trends in averages and standard deviations of AOT values were analyzed to understand changes in the types of aerosol thickness in the study area (Figs. 6 and 7). Pixel values which were remarked under four layers of aerosol thickness (clean, thin, thick, and strong thick) were taken into consideration to determine the areas with dust deposition rates in each month.
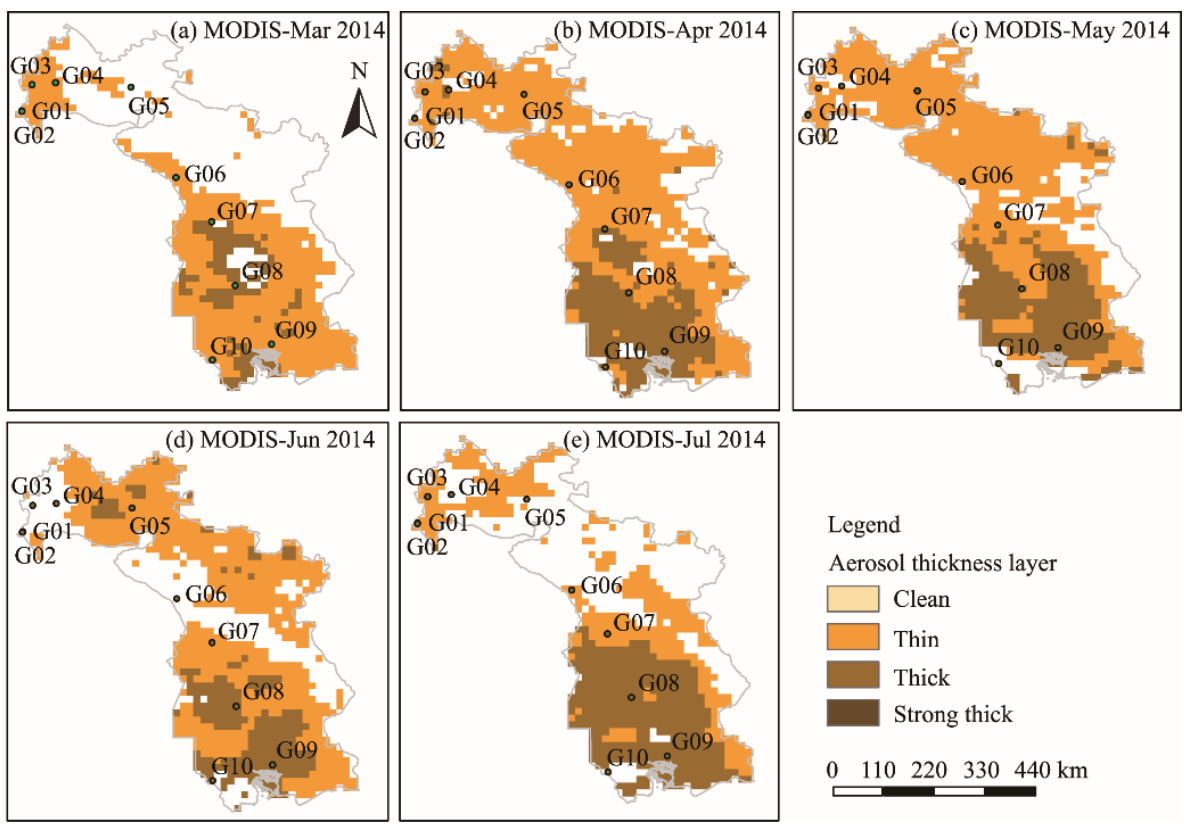

Legend

Aerosol thickness layer

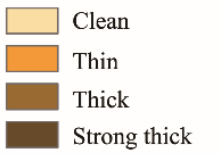

\begin{tabular}{lllll}
0 & 110 & 220 & 330 & 440 \\
\hline
\end{tabular}

Fig. 3 Monthly average aerosol optical thickness (AOT; $550 \mathrm{~nm}$ dark target; $0.1^{\circ}$ resolution) from March to July of 2014
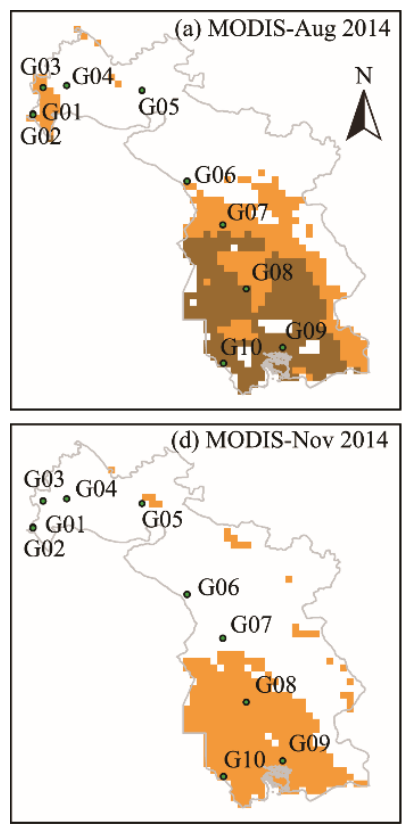
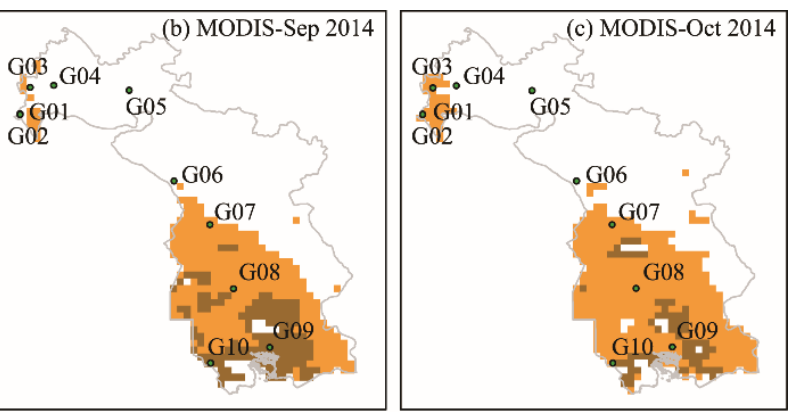

(e) MODIS-Dec 2014

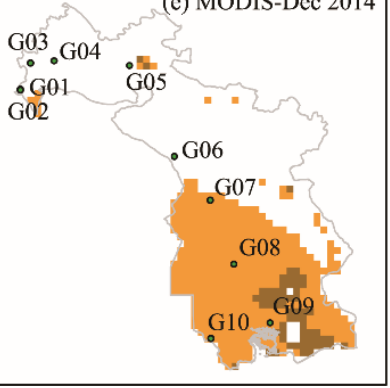

Legend

Aerosol thickness layer

$\square$ Clean

$\square$ Thin

Thick

Strong thick

\begin{tabular}{lllll}
0 & 110 & 220 & 330 & 440 \\
\hline
\end{tabular}

Fig. 4 Monthly average AOT ( $550 \mathrm{~nm}$ dark target; $0.1^{\circ}$ resolution) from August to December of 2014 

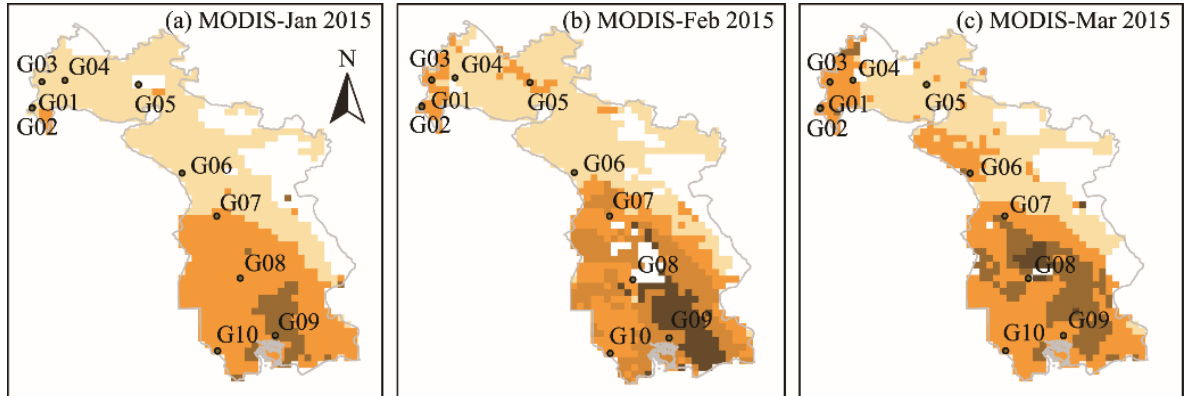

Legend

Aerosol thickness layer

$\square$ Clean $\square$ Thin Thick Strong thick

\begin{tabular}{lllll}
0 & 110 & 220 & 330 & 440 \\
\hline
\end{tabular}

Fig. 5 Monthly average AOT (550 $\mathrm{nm}$ dark target; $0.1^{\circ}$ resolution) from January to March of 2015

-Minimum • Maximum $\bullet$ Median $\triangle \mathrm{SD}+$ Relative counted value
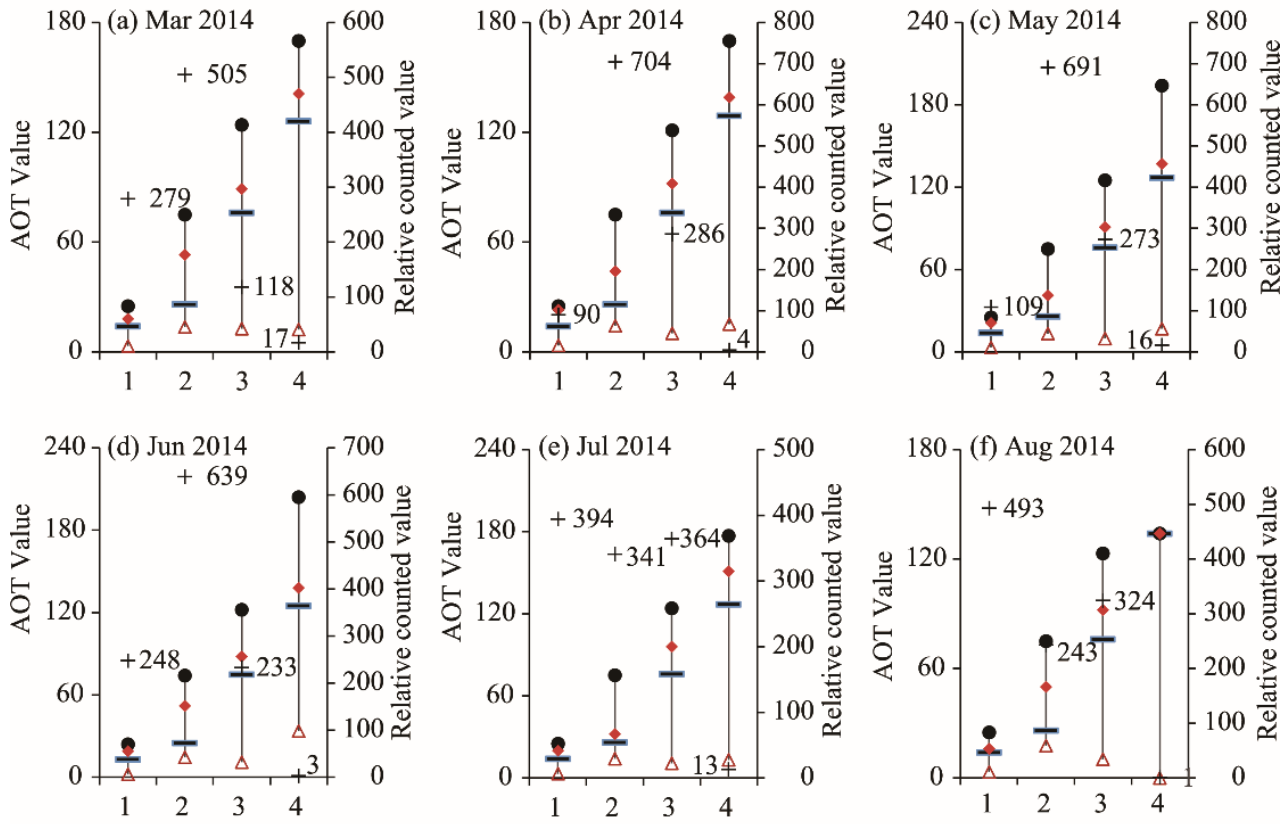

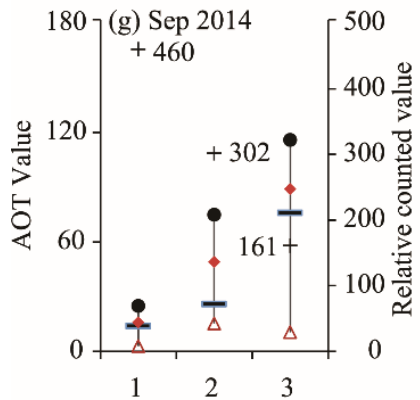

Aerosol thickness layer

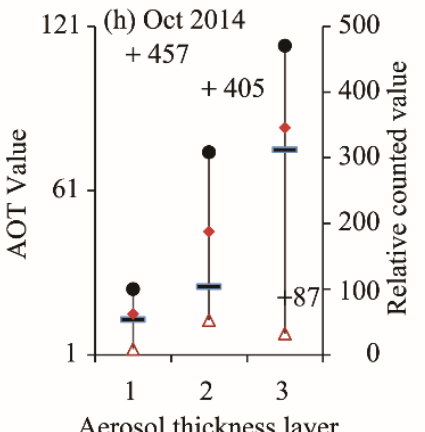

Aerosol thickness layer

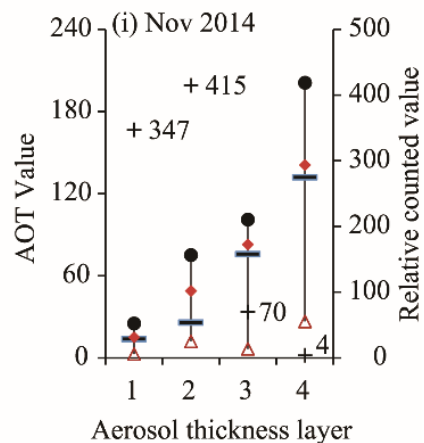

Fig. 6 Temporal monthly means of dark target MODIS AOT (dimensionless) from March to November of 2014. The left $Y$ axis shows modified pixel values which represent the minimum, maximum, median, and standard deviation (SD) values of AOT. The right $Y$ axis shows the relative counted value (counting pixel value) of AOT for each class. For the horizontal axis, 1, 2, 3, and 4 represent the clean, thin, thick, and strong thick layers, respectively. 


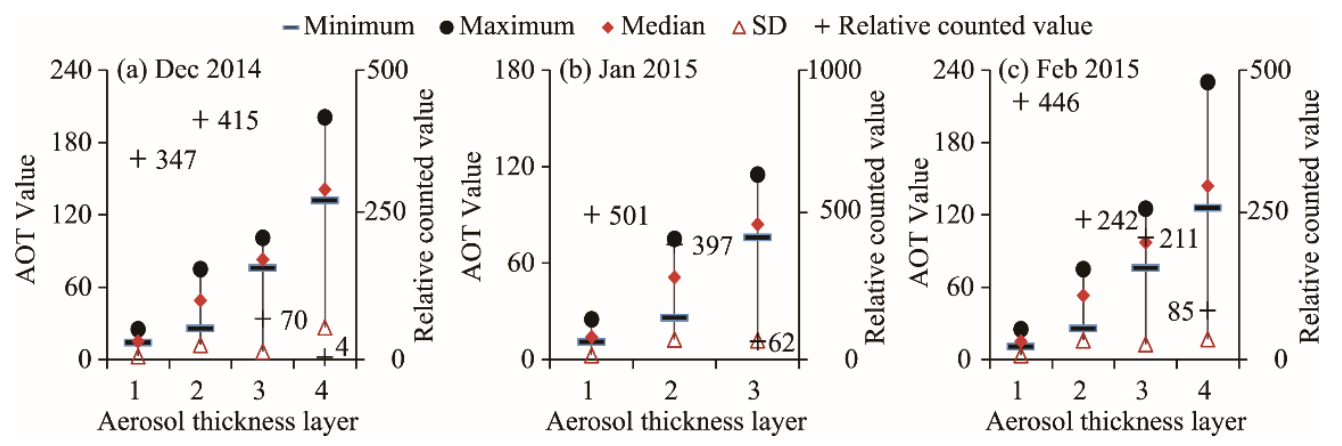

Fig. 7 Temporal monthly means of dark target MODIS AOT (dimensionless) from December 2014 to February 2015. The left $Y$ axis shows modified pixel values which represent the minimum, maximum, median, and standard deviation (SD) values of AOT. The right $Y$ axis shows the relative counted value (counting pixel values) of AOT for each class. For the horizontal axis, 1, 2, 3, and 4 represent the clean, thin, thick, and strong thick layers, respectively.

Figure 6 shows the count-value fluctuation in the monthly trends of the four aerosol thickness layers. It also illustrates the similar trends in AOT values for the thin and thick aerosol thickness classifications, and different variations in terms of extreme dust events such as the strong thick or clean aerosol thickness in the entire study period. In other words, except for autumn and winter, the study area experienced different monthly AOT variations with strong aerosol thickness and higher standard deviations that indicated dust events. In spring and summer, the study area exhibited the highest standard deviations, indicating that it was the region at most risk in terms of extreme dust events. In the detail for April, May, and June, the standard deviations were relatively high in the area of Section C (Fig. 3). The standard deviations in each group of aerosol thickness just reflected the magnitude of variations in the group.

The general trend in the standard deviations decreased in most of the gauge sites during the study period. A specific decline occurred in autumn and winter and was most likely due to the relative counted value of aerosol thickness layers (Figs. 6 and 7).

\subsection{HYSPLIT model output}

The same temporal image data from NASA's MISR were applied to justify AOT. These data likely quantified the ability of AOT collection to retrieve thickness values from the pixel values of each point and were compared to the monthly data for the GDR. In addition to the aforementioned relationship between GDR and the variation of values of the optical thickness layer (strong thick), we characterized the model outputs for summer and spring based on the ground gauge distributions. Therefore, the HYSPLIT model was running for location of endpoints for all sections (A, B, and C; Fig. 8).

As shown in Figure 9, the model output simulated four days backward trajectory in spring and summer based on updrafts loaded for 100, 500, and $1000 \mathrm{~m}$ above ground level, with respect to the above ground surface level. The transport history relative to dust event frequency was shown to the end at 1000 UTC (Universal Time Coordinated) in 29 March 2014. The transport rate originated from the west-north Syria and the Mediterranean Sea, moved southward toward the center of Iraq, and reached Section A, Section B, and Section C.

In contrast, the backward trajectories on 29 April 2014 (Fig. 9) showed trajectory flow derived from the northwest of Saudi Arabia continuing northward to the southeast of Iraq and was observed in both Section A and Section B, while the backward trajectory flow passed directly over Section C from Section B, which can be associated with the local influence flow. AOT mapping was not able to represent the deposition rate in Section A and Section B, including the intensity of the dust transport rate.

The retrieved aerosol mass rate for January 2015 was verified by backward trajectories from the model output. As shown in Figure 10, the transport direction was influenced northward from Saudi Arabia at $1500 \mathrm{~m}$ above ground level, crossing the Persian Gulf and reaching the area of 
Section C. The observation can be verified by the high thickness of pixel values from AOT $(>0.4)$, which were linked to Section C. The observation values in Section B and Section C were mainly arrived from Section A, the same flow with respect to the almost zero above ground level.

The retrieved aerosol distributions on 22 February 2015 demonstrated that high AOT values were linked to the back trajectory at $3500 \mathrm{~m}$ above ground level from the Mediterranean Sea, the extreme north of Saudi Arabia, and through southern Iraq, and reached the area of Section A.

The transport direction confirmed the impact of local dust contributions from the southern Iraq adding to the surface layer before deposition in Section B. This could also illustrate the cause of different dust event situations in Section A. Maximum AOT values were combined with more intense flow from the north at $1000 \mathrm{~m}$ above ground level and with dust flow from long distance transports directed from the southern Iraq and the Mediterranean Sea.

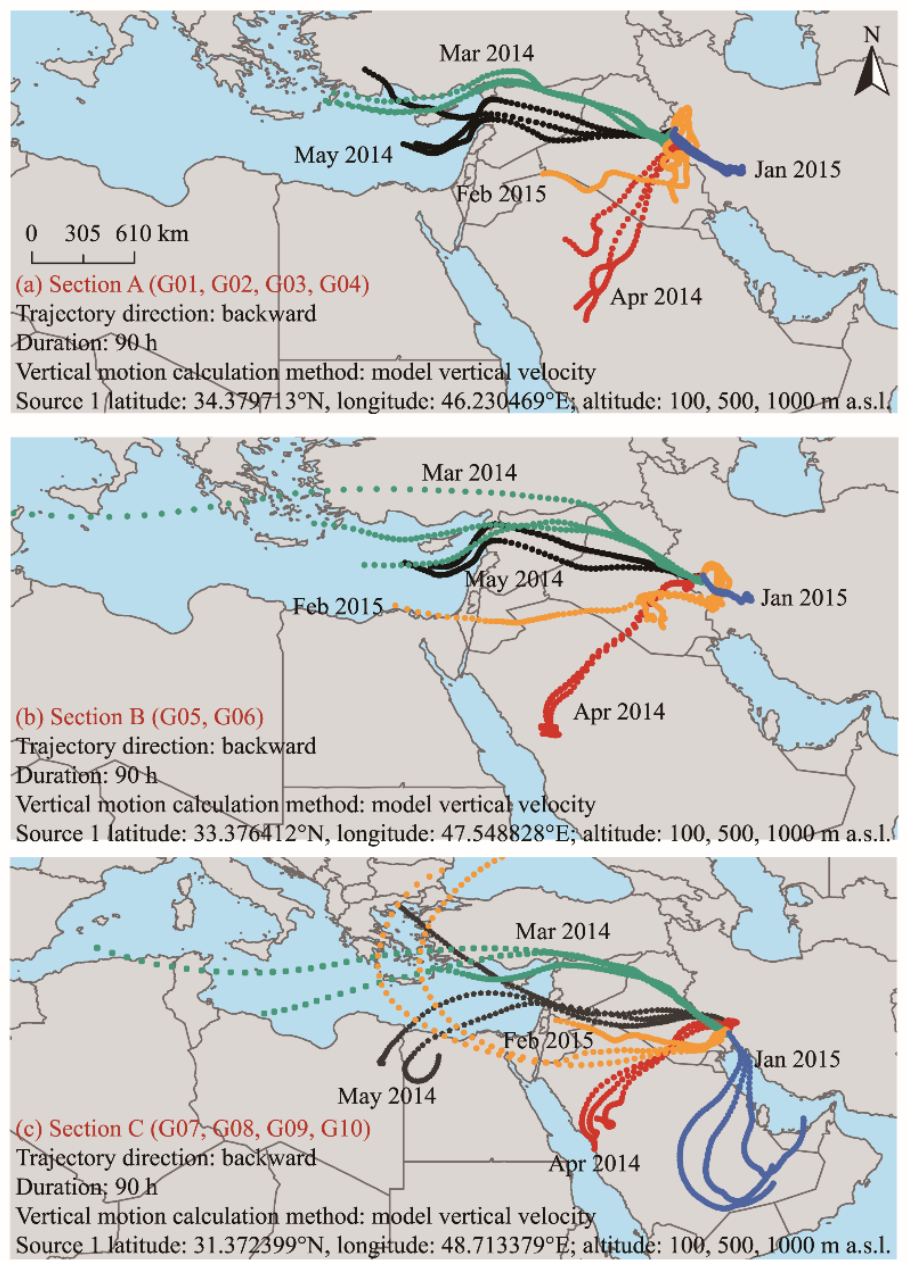

Fig. 8 Model output from Hybrid Single-Particle Lagrangian Integrated Trajectory (HYSPLIT) for Section A (a), Section B (b), and Section C (c). Transport history relative on dust event frequency was simulated four days backward trajectories for an ending time at 1000 UTC (Universal Time Coordinated) in January and February of 2015, and March, April, and May of 2014. AGL, above ground level.

\section{Discussion}

In this study, we compared MODIS and MISR data with similar data from sampling periods preceding and following the dust events in order to validate the optical thickness of MODIS and MISR. Accordingly, the results of evaluating these data focusing on the retrieved AOT values and their differences and correlations are represented. 

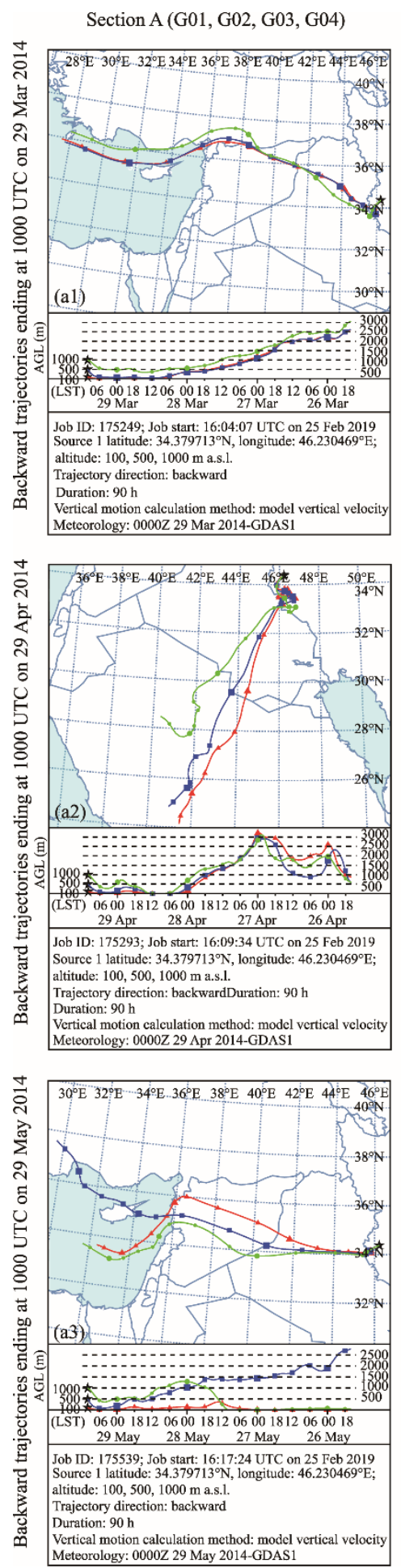

Section B (G05, G06)
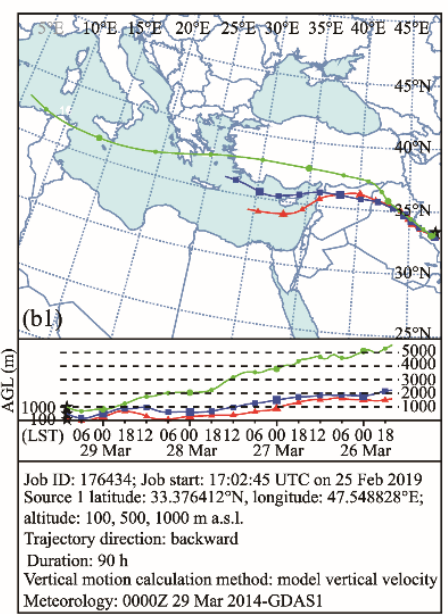

Meteorology: 0000Z 29 Mar 2014-GDAS1
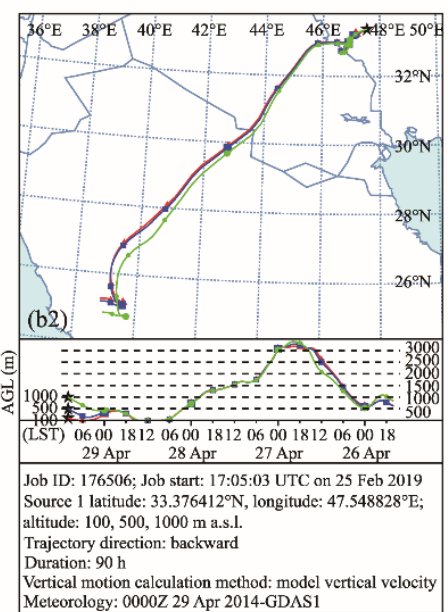

Meteorology: 0000Z 29 Apr 2014-GDAS1
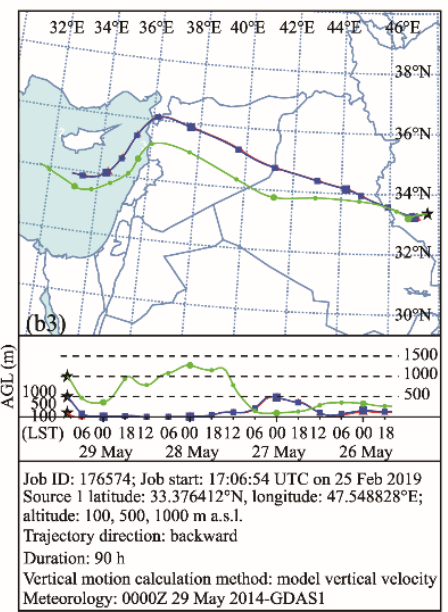

Section C (G07, G08, G09, G10)
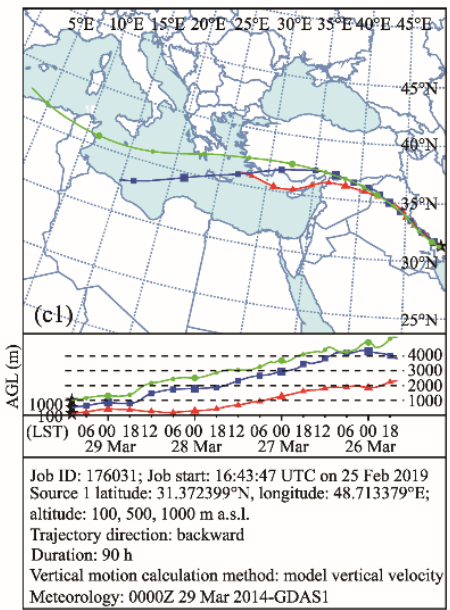

Meteorology: 0000Z 29 Mar 2014-GDAS1
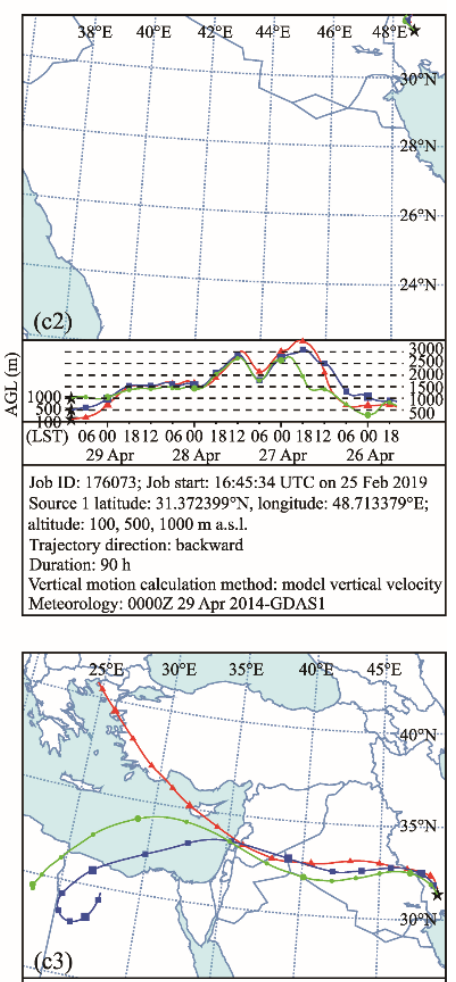

(c3)

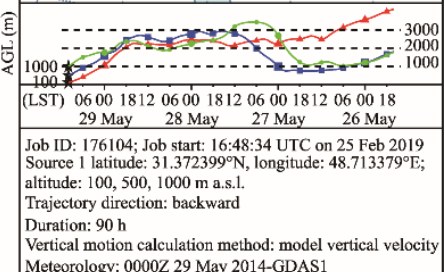

Fig. 9 Model output simulated four days backward trajectories from HYSPLIT in March, April, and May of 2014. It is based on updrafts loaded for 100,500 , and $1000 \mathrm{~m}$ above ground level, with respect to the above ground surface level. Flows in March, April, and May of 2014 reached Section A, Section B, and Section C from the same direction. In April, however, Section C was more influenced from local processes. High fluctuation intensities were observed with a steady decline to ending points in March 2014. More intensity in vertical velocity was observed in April and May of 2014. 

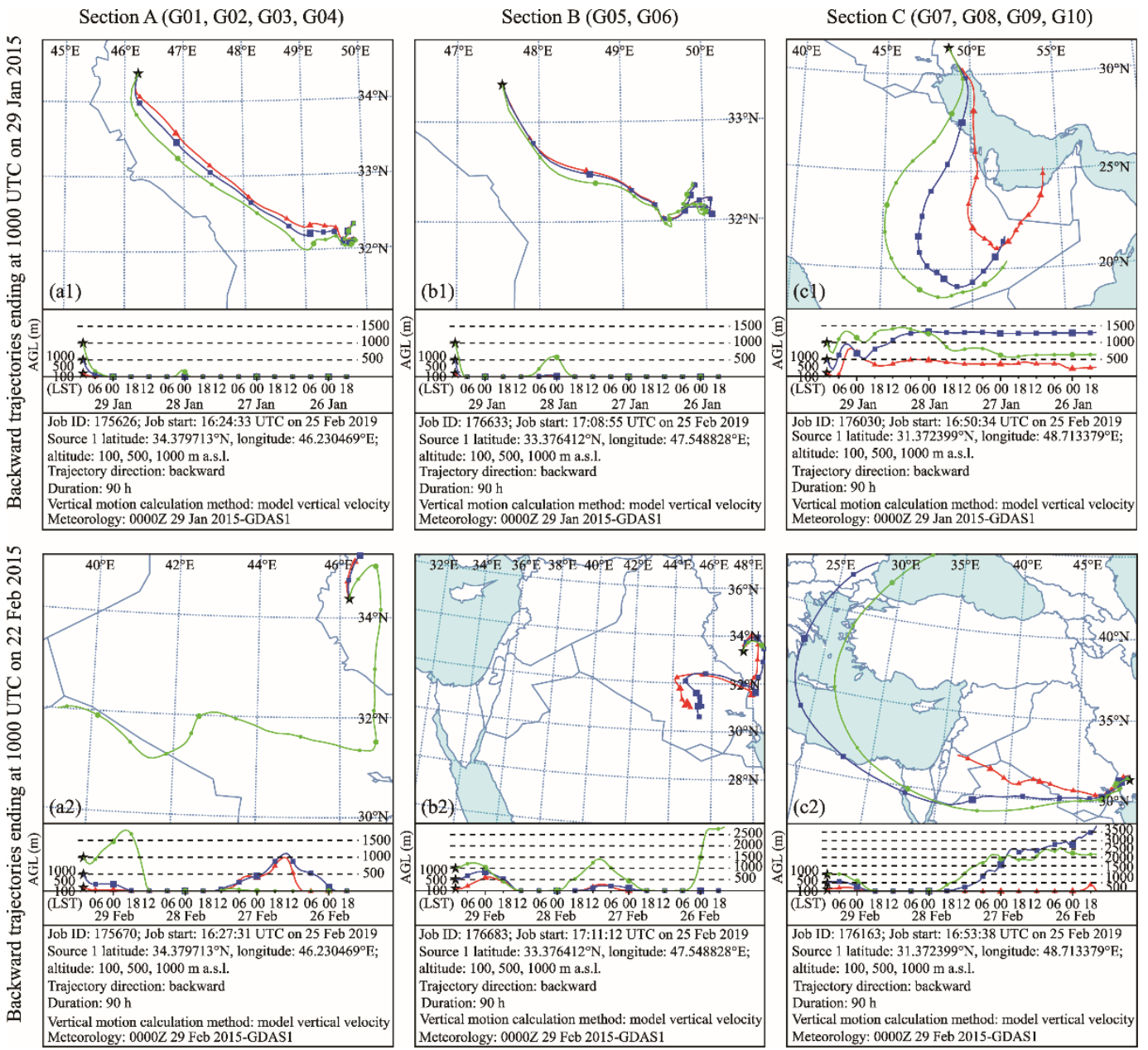

Fig. 10 Model output simulated four days backward trajectories from HYSPLIT in January and February of 2015. It is based on updrafts loaded for 100, 500, and $1000 \mathrm{~m}$ above ground level, with respect to the above ground surface level. Transport history relative to dust event frequency showed an ending time at 1000 UTC on 29 January and 22 February, 2015. For all sections (A, B, and C), high fluctuation intensities were observed in February 2015.

MODIS and MISR onboard the Earth Observing System (Diner et al., 1998) have been extensively used for global dust observations (Xiao et al., 2009). In particular, the AOT product retrieved from visible and near infrared data can be used to monitor dust events (Washington et al., 2003; Levy and Hsu, 2015). The general patterns of the global aerosol fields retrieved by MODIS and MISR are remarkably similar (Hu, 1990), indicating a high comparability of both data products (e.g., Geogdzhayev et al., 2004; Huang et al., 2007; Wang et al., 2011). The case studies for this can be found for many different dust areas with attention to the Sahara Desert (Zhang et al., 2003; Koren et al., 2006; Schepanski et al., 2017), the Persian Gulf (Liu and Mishchenko, 2008; Banks et al., 2017), the Tarim River Basin in northwestern China (e.g., Yan et al., 2006), as well as the Indian subcontinent (e.g., di Girolamo et al., 2004; Jethva et al., 2007), including the Southern Hemisphere (e.g., Wu et al., 2009). In fact, the magnitude of AOT differed between MODIS and MISR (Levy and Hsu, 2015) and its values had apparent seasonal variations (Yan et al., 2006; Jiang et al., 2007). The observations from the same locations in different seasons have shown that MODIS performed better particularly in summer due to the relatively higher vegetation cover (Prasad and Singh, 2007). In fact, MODIS aerosol retrieval method is unable to find dark pixels within the surface albedo channel (Levy and Hsu, 2015), while MISR can retrieve optical properties over a variety of terrains (Diner et al., 2001; Martonchik et al., 
2004). Equally important, Diner et al. (2001) showed that the derived AOT from MISR has a positive bias of 0.02 and an overestimate of $10 \%$ when compared to ground-based observations. That is to say, mean AOT derived from MISR is systematically larger than that from MODIS, which can be attributed to a relative calibration offset (Liu and Mishchenko, 2008).

With this in mind, we computed Pearson's correlation coefficients using monthly average level 3 MODIS (MOD08_M3 v6.1) and MISR (MIL3MAE v4) data. Monthly seasonal data from January, February, and March of 2015 as well as from March, April, and May of 2014 were used to calculate the correlation coefficients. Figure 11 shows that the correlation coefficients for MODIS scattering MISR were relatively high during May $\left(R^{2}=0.710\right)$ and moderate in April $\left(R^{2}=0.568\right)$, while the correlation was only slightly above the moderate level in March $\left(R^{2}=0.447\right)$. In agreement with Prasad and Singh (2007) and reinforced by Liu and Mishchenko (2008), the mean of absolute differences of the averages of MODIS and MISR explains seasonal variations in March and May compared to MODIS over the area of Section C in April.
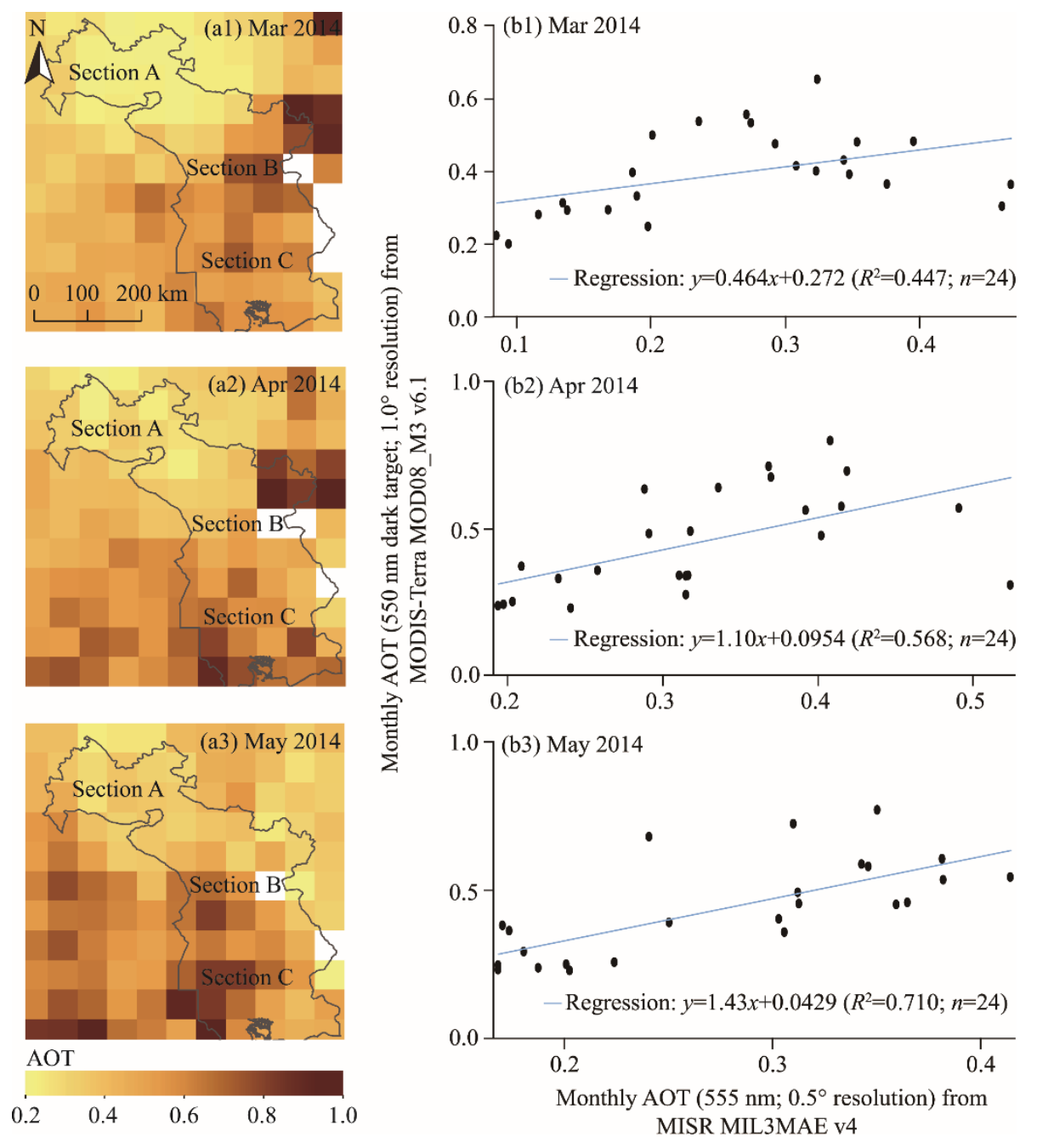

Fig. 11 AOT of Multi-angle Imaging SpectroRadiometer (MISR) images with a spatial resolution of $0.5^{\circ}$ in March, May, and April of 2014 (a1, a2, and a3, respectively), and scattering plots showing the correlation between two sets of AOT from MISR and MODIS in March, May, and April of 2014 (b1, b2, and b3, respectively). Latitude: $30.5^{\circ}-34.5^{\circ} \mathrm{N}$; longitude: $45.5^{\circ}-49.5^{\circ} \mathrm{E}$.

It can also be seen in Figure 12 that the correlation coefficients were relatively high for MODIS-MISR in February $\left(R^{2}=0.727\right)$ and March $\left(R^{2}=0.729\right)$ of 2015. In addition, the observed correlation coefficient in January $\left(R^{2}=0.649\right)$ agreed very well with similar findings about 
seasonal variations retrieved from Yan et al. (2006) and Huang et al. (2007). Similarly, the mean of absolute differences from the monthly average between MODIS and MISR is consistent with the MODIS-derived AOT disability to identify dark pixels (Levy and Hsu, 2015). Also in agreement with Prasad and Singh (2007) and given the good correlation of the global AOT of MODIS and MISR, we found that MODIS provided better results for the study area in March, April, and May due to high vegetation covers in sections A, B, and C.
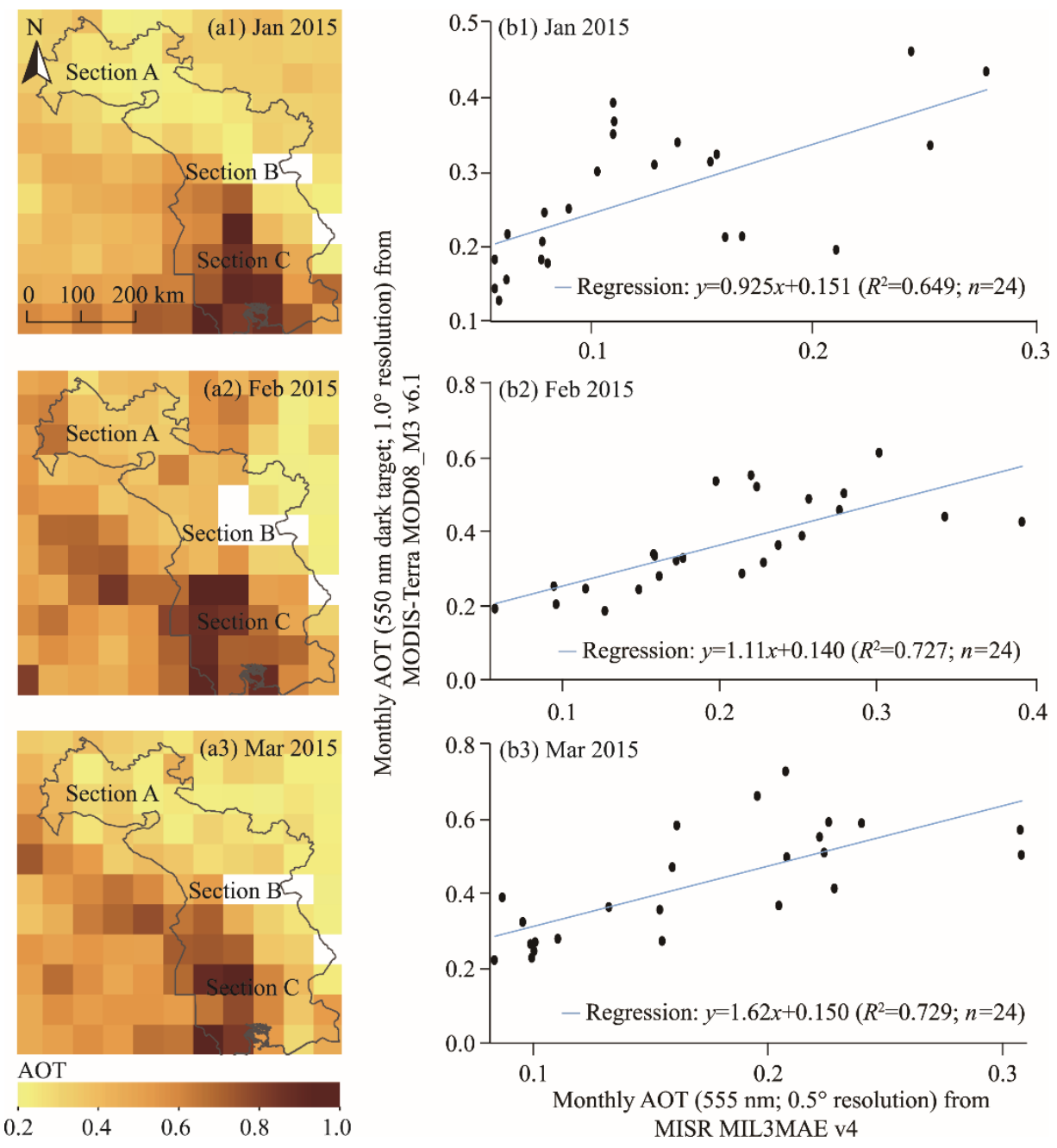

Fig. 12 AOT of MISR images with a spatial resolution of $0.5^{\circ}$ in January, February, and March of 2015 (a1, a2, and a3), and scattering plots showing the correlation between two sets of AOT from MISR and MODIS in January, February, and March of 2015 (b1, b2, and b3). Latitude: $30.5^{\circ}-34.5^{\circ} \mathrm{N}$; longitude: $45.5^{\circ}-49.5^{\circ} \mathrm{E}$.

With attention to seasonal ecological changes (e.g., Gao, 2000), results describing seasonal variation of dust events can be related to ecological and climatological characteristics of the environments. Prominent seasonal dust events have been reported during spring and summer in the Sistan region of eastern Iran (Abbasi et al., 2018). New contribution to the northeast part of Iran suggested that the highest rates of atmospheric dust occurred in summer (Ziyaee et al., 2018). However, recent studies from Central Asia showed an increase in the seasonal dust deposition rate from spring to autumn (Groll et al., 2013; Opp et al., 2017) in the Aral Sea region for the period from 2003 to 2012. Five dust storms have been reported in southwestern Iran during springtime of 2011, 2012 (Najafi et al., 2014), and 2014 (Foroushani et al., 2019). Moreover, dust loads from Africa and Asia were transported into the Arctic and deposition reached a maximum rate in spring (Stohl, 2006; Quinn et al., 2007; Breider et al., 2014). Fiedler et al. (2014) reported that about 
$25 \%$ of the total dust emissions from the Sahara occurred in spring due to seasonal cyclones over North Africa. As can be seen from Figures 9, 11, and 12, the very similar backward trajectories distribution implied comparable wind directions and dust events in March and May of 2014. Note that more than $30 \%$ of all air masses in February 2015 were derived from the Mediterranean Sea, while twice as much was received from Saudi Arabia and Iraq in April 2014 and January 2015.

According to previous studies (Fig. 13), AOT values ranged from 0.1 to 1.0 in a dusty environment and were higher in polluted regions to enumerate the principal thickness (Schaap et al., 2008; Remer et al., 2009; Levy and Hsu, 2015). The Angstrom exponent describes how the AOT typically depends on the wavelength of the light. The smaller value of AOT, the smaller the exponent.

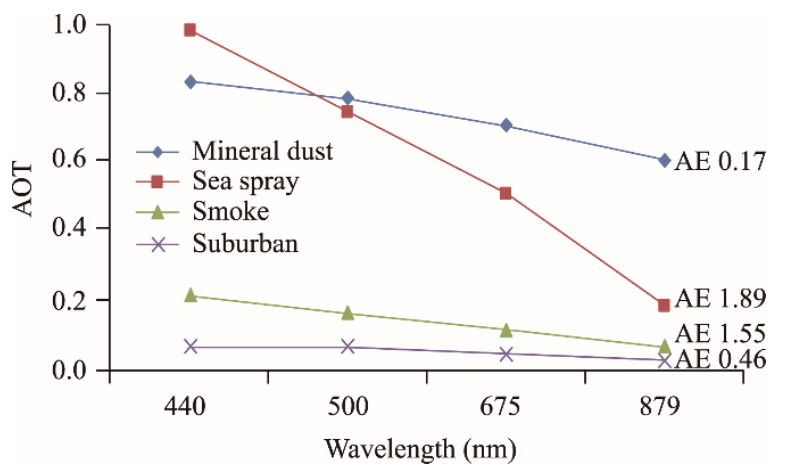

Fig. 13 Thickness properties by courtesy of NASA for AOT user manual retrieved from Collection 6.0 MODIS data in a publication of Levy and Hsu (2015). AE, angstrom exponent.

This is a measure of how much light the airborne particles prevent from traveling through the atmosphere (Stockli and Jentoft, 2013). A lower optical aerosol thickness likely would have less impact on radiative forcing (Dubovik et al., 2002), while dense aerosols absorb and scatter incoming sunlight more effectively, thus reducing visibility and increasing optical thickness (Schaap et al., 2008). The variance in the layers is consistent with the finding of Levy and Hsu (2015), that is, an optical aerosol thickness of less than 0.1 indicates a clear sky with maximum visibility, whereas a value of 1.0 means the presence of extreme density and very low visibility even at mid-day (Remer et al., 2009). In hypothesis testing, AOT should be pronounced the same variation as GDR collected in the study period. Four layers of aerosol thickness therefore, were plotted to identify which one follows the variation in GDR most closely. Figure 14 shows the spatial gradient in AOT over the study area as calculated.

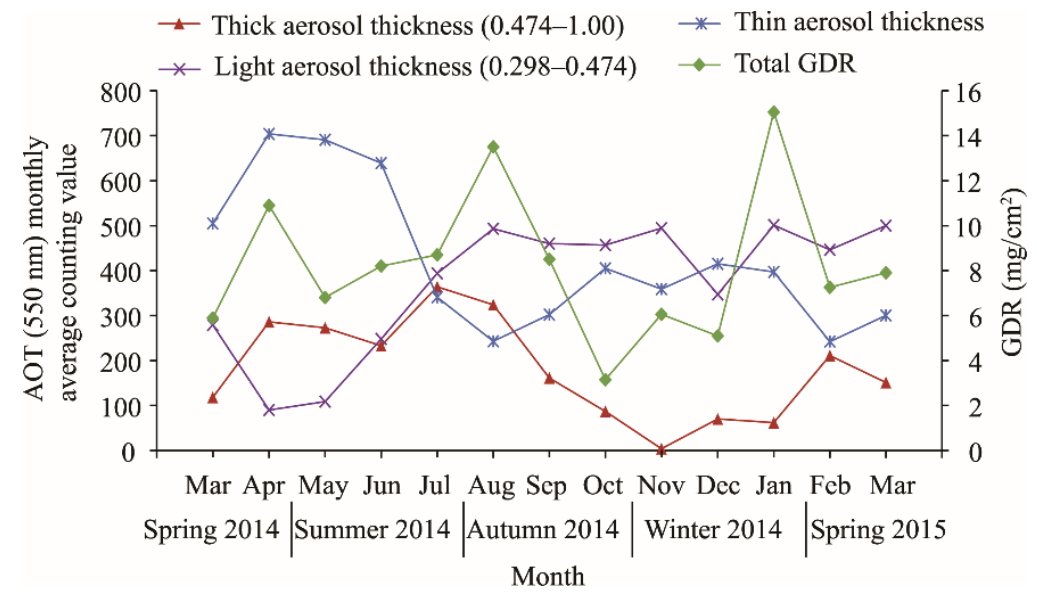

Fig. 14 Plotting spatial gradient in AOT compared with the fluctuation values of ground deposition rate (GDR) 
Each aerosol layer has a group of pixel values (0.0-1.0), with a classification of clean, thin, thick, and strong thick aerosol thickness layers. The pixel-value count for each layer was plotted on the primary $Y$ axis while GDR values $\left(\mathrm{mg} / \mathrm{cm}^{2}\right)$ were placed on the secondary $Y$ axis. All layers' thicknesses, derived from AOT, were highest in spring and summer, with the maximum values of 501 (clean aerosol thickness layer) and 704 (thin aerosol thickness layer), respectively. In autumn, the maximum value (364) was observed in thick aerosol thickness layer. Additionally, a strong thickness was detected in strong thick aerosol thickness layer during spring with a maximum magnitude of 85 . In general, the results in Figure 15 revealed that the observed GDR-MODIS correlation from March 2014 to March 2015 is indicative of a significant correlation with the thickness increase across the study area, especially in thick and strong thick aerosol thickness layers.
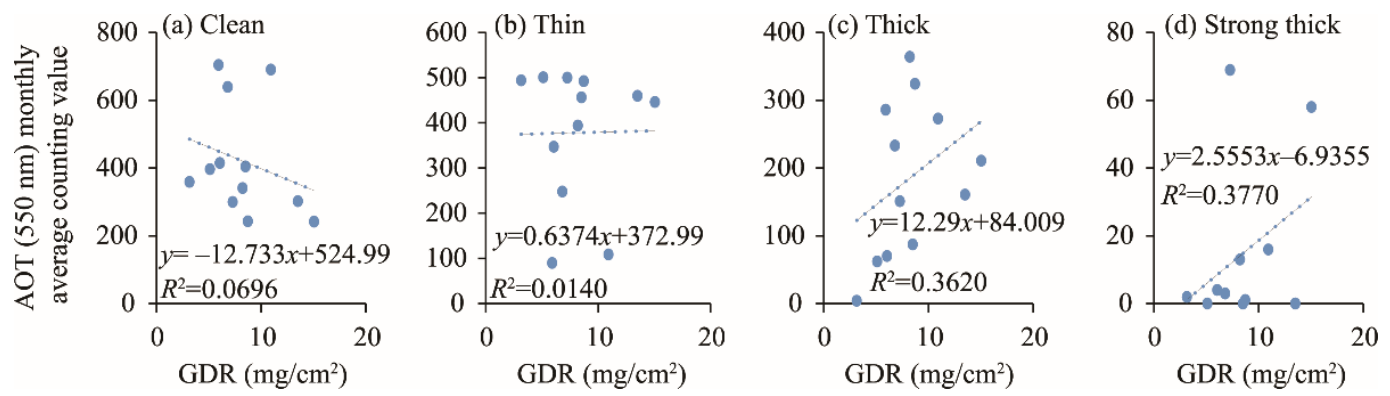

Fig. 15 Correlation between atmospheric dust loading and dust accumulation. Layers are classified in clean (a), thin (b), thick (c), and strong thick (d) from March 2014 to 2015

In accordance with Remer et al. (2009) and Levy and Hsu (2015), and the overall trends illustrated in Figure 15, thick and strong thick aerosol thickness layers had notable magnitudes of correlation of $36 \%$ and $38 \%$, respectively. Whereas, clean and thin aerosol thickness layers were represented as having almost negative or zero correlation, which is similar to the classification by Dubovik et al. (2002) and the MODIS data guidance from Levy and Hsu (2015). Results from comparisons of quantitative AOT retrieval could evaluate that the clean and thin aerosol thickness layers had some uncertainties in screening the GDR. With the results from negative and zero correlation values in clean and thin aerosol thickness layers, respectively, alpha levels were higher than the level of significance $(P>0.05$ and probability of $98 \%$ confidence). Based on that, and in agreement with previous contributions about thickness classifications (Dubovik et al., 2002; Stockli and Jentoft, 2013; Levy and Hsu, 2015), we hence removed the clean and thin aerosol thickness layers of AOT from further calculations. Unlike the clean and thin aerosol thickness layers, the thick aerosol thickness layer, together with the strong thick aerosol thickness layer, had almost the same variation as has been observed from GDR. As can be seen from Figure 16, high layer variations were identified in spring and summer while only small changes were observed in autumn and winter.

Differences from the gradients of thick and strong thick aerosol thickness layers across all four season were identified as the same fluctuation values as for GDR and showed a high correlation coefficient. This is also supported by the elevated AOT identified during spring and summer in southwestern Iran (Sabetghadam et al., 2018). These results are in great agreement with previously published evidences (Schaap et al., 2008; Remer et al., 2009; Levy and Hsu, 2015), which obtained the annual average AOT values from MODIS. In order to make the best use of satellite data and reduce the uncertainty of aerosol effects on regional and global climate, we recommended that these satellite measurements need to be validated using ground-based observations. Intercomparison and validation of satellite products from different instruments with ground-based observations could reveal interesting details and allow building a long term database of aeolian dust deposition rates. 


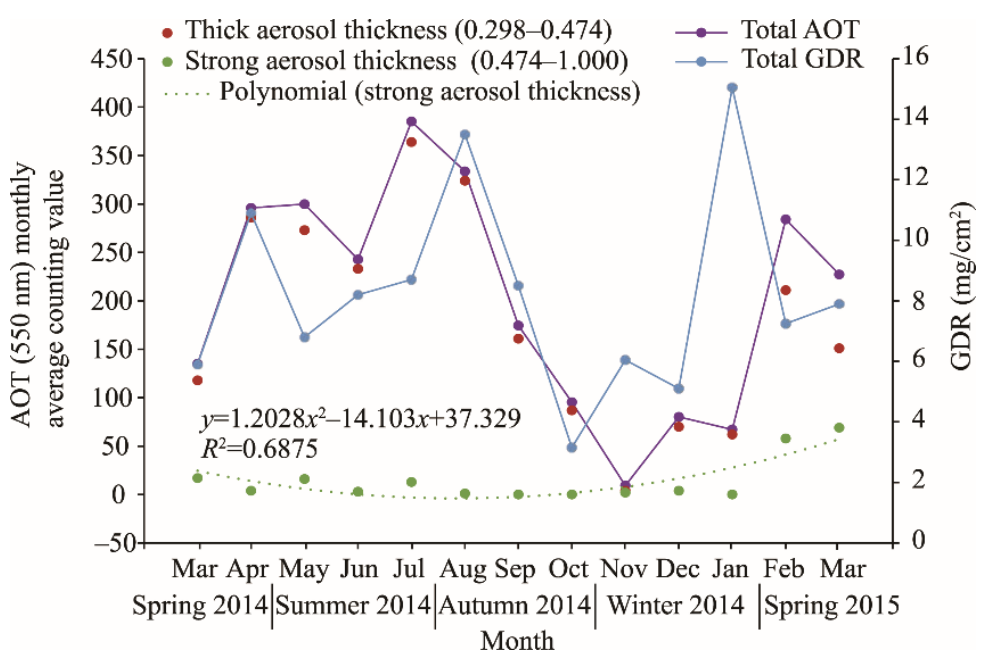

Fig. 16 Plotting AOT (thick and strong thick aerosol thickness layers) with the fluctuation values of GDR

\section{Conclusions and remarks}

This study focused on the enhancement of dust deposition rates in southwestern Iran. The ground deposition rates and geographical variations in dust event frequency were well demonstrated. The composite product data from MODIS and MISR on Terra satellite were also addressed.

The findings suggested that, despite a slightly better estimation from MISR when the sections $\mathrm{A}, \mathrm{B}$, and $\mathrm{C}$ were affected by a number of dust events, MODIS showed a better performance overall. The comparison of AOT derived from MODIS and GDR over the study area showed a good agreement and approximately $65 \%$ of GDR fell within AOT limitations with uncertainty.

Under the four layer classifications of aerosol thickness: clean, thin, thick, and strong thick, the standard MODIS aerosol products were applied at regional scales to monitor both dust distributions and transportation directions. However, the $1.0^{\circ}$ and even the $0.5^{\circ}$ spatial resolution data are insufficient to depict the deposition rate at local scales due to inherent dust variabilities, as well as the complexity of the land surfaces.

In general, AOT retrieval can represent the strong seasonal and geographical variations in dust deposition rates and their regional distributions. But due to the methodological limitations of these remote sensing approaches, significant uncertainties remain and the possibilities to further understanding the knowledge of dust deposition rates and frequencies in a high spatiotemporal resolution are limited. Thus, combining remote sensing and ground-based dust research is, in many cases, vital to estimate real-world effects of dust on the sink regions.

Although high spatial resolution products with a chronological record are suitable basics for the improvement of dust deposition analyses and ecosystem effect assessments, ground surveys are still a key point for analyzing airborne deposition. However, the deposition rates based on space model algorithms (i.e., AOT) remain the method of choice, even though they are relatively complicated and less accurate than ground surface observations (i.e., GDR), due to the lack of continuous atmospheric data at required scales over the area of interest. Besides, the development of ground survey algorithms is necessary to make the estimations of deposition rates more accurately. Therefore, current detection algorithms could be modified based on the technology of machine learning from physical characteristics, and spatial and temporal distributions.

\section{Acknowledgements}

The authors would like to thank IRIMO (Iranian Meteorological Organization) for providing observation data for this research and MODIS Giovanni and NEO/NASA for their technical assistance and useful data. The authors gratefully acknowledge the NOAA Air Resources Laboratory Team (ARL) for providing the HYSPLIT transport and dispersion model online. 


\section{References}

Abbasi H R, Opp C, Groll M, et al. 2018. Spatial and temporal variation of the aeolian sediment transport in the ephemeral Baringak Lake (Sistan Plain, Iran) using field measurements and geostatistical analyses. Zeitschrift Für Geomorphologie, 61(4): 315-326.

Abdou W A, Diner D J, Martonchik J V, et al. 2005. Comparison of coincident Multiangle Imaging Spectroradiometer and Moderate Resolution Imaging Spectroradiometer aerosol optical depths over land and ocean scenes containing Aerosol Robotic Network sites. Journal of Geophysical Research: Atmospheres, 110(D10): D10S07, doi: 10.1029/2004jd004693.

Alizadeh C O, Zawar-Reza P, Sturman A. 2013. Low level jet intensification by mineral dust aerosols. Annales Geophysicae, 31(4): 625-632.

Arimoto R, Ray B J, Lewis N F, et al. 1997. Mass-particle size distributions of atmospheric dust and the dry deposition of dust to the remote ocean. Journal of Geophysical Research: Atmospheres, 102(D13): 15867-15874.

Ashrafi K, Shafiepour-Motlagh M, Aslemand A, et al. 2014. Dust storm simulation over Iran using HYSPLIT. Journal of Environmental Health Science and Engineering, 12(1): 9, doi: 10.1186/2052-336x-12-9.

ASTER Science Team. 2001. NASA EOSDIS Land Processes DAAC [Map]. NASA/METI/AIST/Japan Space Systems, and U.S./Japan. [2017-11-05]. https://lpdaac.usgs.gov/products/astgtmv002/.

Balakrishnaiah G, Kumar K R, Reddy B S K, et al. 2012. Spatio-temporal variations in aerosol optical and cloud parameters over southern India retrieved from MODIS satellite data. Atmospheric Environment, 47: 435-445.

Banks J R, Brindley H E, Stenchikov G, et al. 2017. Satellite retrievals of dust aerosol over the Red Sea and the Persian Gulf (2005-2015). Atmospheric Chemistry and Physics, 17(6): 3987-4003.

Bieringer P E, Young G S, Rodriguez L M, et al. 2017. Paradigms and commonalities in atmospheric source term estimation methods. Atmospheric Environment, 156: 102-112.

Binietoglou I, Basart S, Alados-Arboledas L, et al. 2015. A methodology for investigating dust model performance using synergistic EARLINET/AERONET dust concentration retrievals (Discussion paper). Atmospheric Measurement Techniques, 8: $3577-3600$.

Breider T J, Mickley L J, Jacob D J, et al. 2014. Annual distributions and sources of Arctic aerosol components, aerosol optical depth, and aerosol absorption. Journal of Geophysical Research: Atmospheres, 119(7): 4107-4124.

Cazacu M M, Tudose O, Balanici D, et al. 2018. Research and development of commercial lidar systems in Romania: Critical review of the ESYRO lidar systems developed by scenviroscopy SRL (ESYRO). European Physical Journal Conferences, 176: 11005, doi: 10.1051/epjconf/201817611005.

Cesnulyte V, Lindfors A V, Pitkänen M R A, et al. 2014. Comparing ECMWF AOD with AERONET observations at visible and UV wavelengths. Atmospheric Chemistry and Physics, 14(2): 593-608.

Chai T, Draxler R, Stein A. 2015. Source term estimation using air concentration measurements and a Lagrangian dispersion model: Experiments with pseudo and real cesium-137 observations from the Fukushima nuclear accident. Atmospheric Environment, 106: 241-251.

Chen B, Stein A F, Maldonado P G, et al. 2013. Size distribution and concentrations of heavy metals in atmospheric aerosols originating from industrial emissions as predicted by the HYSPLIT model. Atmospheric Environment, 71: 234-244.

Crosbie E, Youn J S, Balch B, et al. 2015. On the competition among aerosol number, size and composition in predicting CCN variability: A multi-annual field study in an urbanized desert. Atmospheric Chemistry and Physics, 15(12): 6943-6958.

de Longueville F, Ozer P, Doumbia S, et al. 2013. Desert dust impacts on human health: An alarming worldwide reality and a need for studies in West Africa. International Journal of Biometeorology, 57(1): 1-19.

di Girolamo L, Bond T, Bramer D, et al. 2004. Analysis of Multi-angle Imaging SpectroRadiometer (MISR) aerosol optical depths over greater India during winter 2001-2004. Geophysical Research Letters, 31(23): 1-5.

Dindaroğlu T. 2014. The use of the GIS Kriging technique to determine the spatial changes of natural radionuclide concentrations in soil and forest cover. Journal of Environmental Health Science and Engineering, 12(1): 130-130.

Diner D J, Beckert J C, Reilly T H, et al. 1998. Multi-angle Imaging SpectroRadiometer (MISR) instrument description and experiment overview. IEEE Transactions on Geoscience and Remote Sensing, 36(4): 1072-1087.

Diner D J, Abdou W A, Bruegge C J, et al. 2001. MISR aerosol optical depth retrievals over southern Africa during the SAFARI-2000 dry season campaign. Geophysical Research Letters, 28(16): 3127-3130.

Draxler R R, Hess G. 1998. An overview of the HYSPLIT_4 modelling system for trajectories, dispersion, and deposition. Australian Meteorological Magazine, 47(4): 295-308.

Dubovik O, Holben B, Eck T F, et al. 2002. Variability of absorption and optical properties of key aerosol types observed in worldwide locations. Journal of the Atmospheric Sciences, 59(3): 590-608. 
Fiedler S, Schepanski K, Knippertz P, et al. 2014. How important are atmospheric depressions and mobile cyclones for emitting mineral dust aerosol in North Africa? Atmospheric Chemistry and Physics, 14(17): 8983-9000.

Foroushani M A, Opp C, Groll M. 2019. Chemical characterization of aeolian dust deposition in southern and western Iran. Asian Journal of Geographical Research, 2(2): 1-22.

Franklin M, Kalashnikova O V, Garay M J, et al. 2018. Characterization of subgrid-scale variability in particulate matter with respect to satellite aerosol observations. Remote Sensing, 10(4): 623, doi: ARTN 623 10.3390/rs10040623.

Gao Q, Li L, Zhang Y, et al. 2000. Studies on the springtime dust storm of China. China Environmental Science, 20(6): 495500. (in Chinese)

Geogdzhayev I V, Mishchenko M I, Liu L, et al. 2004. Global two-channel AVHRR aerosol climatology: Effects of stratospheric aerosols and preliminary comparisons with MODIS and MISR retrievals. Journal of Quantitative Spectroscopy and Radiative Transfer, 88(1-3): 47-59.

Gerivani H, Lashkaripour G R, Ghafoori M, et al. 2011. The source of dust storm in Iran: A case study based on geological information and rainfall data. Carpathian Journal of Earth and Environmental Sciences, 6(1): 297-308.

Golitsyn G, Gillette D A. 1993. Introduction: A joint soviet-American experiment for the study of Asian desert dust and its impact on local meteorological conditions and climate. Atmospheric Environment. Part A. General Topics, 27(16): 24672470.

Groll M, Opp C, Aslanov I. 2013. Spatial and temporal distribution of the dust deposition in Central Asia-results from a long term monitoring program. Aeolian Research, 9: 49-62.

Hu H. 1990. The distribution, regionalization and prospect of China's population. Acta Geographica Sinica, 57(2): 139-145.

Huang J, Minnis P, Yan H, et al. 2010. Dust aerosol effect on semi-arid climate over Northwest China detected from A-Train satellite measurements. Atmospheric Chemistry and Physics, 10(14): 6863-6872.

Huang J P, Minnis P, Yi Y H, et al. 2007. Summer dust aerosols detected from CALIPSO over the Tibetan Plateau. Geophysical Research Letters, 34(18), doi: 10.1029/2007g1029938.

Hutchinson M, Oh H, Chen W H. 2017. A review of source term estimation methods for atmospheric dispersion events using static or mobile sensors. Information Fusion, 36: 130-148.

IHS under License with ASTM. 2010. Standard Terminology Relating to Sampling and Analysis of Atmospheres. IHS under License with ASTM. [2014-12-25]. https://wenku.baidu.com/view/8324a4b765ce050876321358.

Iran Meteorological Organization. 2014. Precipitation Map. [2015-09-15]. http://www.irimo.ir/index.php?newlang=eng.

IRMO. 2016. I.R.OF IRAN Meteorological Organization. Dust National Center. [2015-09-15]. http://www.irimo.ir/far/index.php.

Jethva H, Satheesh S, Srinivasan J. 2007. Assessment of second-generation MODIS aerosol retrieval (Collection 005) at Kanpur, India. Geophysical Research Letters, 34(19), doi: 10.1029/2007GL029647.

Jiang X, Liu Y, Yu B, et al. 2007. Comparison of MISR aerosol optical thickness with AERONET measurements in Beijing metropolitan area. Remote Sensing of Environment, 107(1-2): 45-53.

Kaufman Y J, Koren I. 2006. Smoke and pollution aerosol effect on cloud cover. Science, 313(5787): 655-658.

Kharazmi R, Tavili A, Rahdari M R, et al. 2018. Monitoring and assessment of seasonal land cover changes using remote sensing: A 30-year (1987-2016) case study of Hamoun Wetland, Iran. Environmental Monitoring and Assessment, 190(6): 356, doi: 10.1007/s10661-018-6726-z.

Kim H S, Chung Y S, Kim J T. 2014. Spatio-temporal variations of optical properties of aerosols in East Asia measured by MODIS and relation to the ground-based mass concentrations observed in central Korea during 2001-2010. Asia-Pacific Journal of Atmospheric Sciences, 50(2): 191-200.

Koren I, Kaufman Y J, Washington R, et al. 2006. The Bodélé depression: A single spot in the Sahara that provides most of the mineral dust to the Amazon forest. Environmental Research Letters, 1(1): 014005, doi: 10.1088/1748-9326/1/1/014005.

Lawrence C R, Neff J C. 2009. The contemporary physical and chemical flux of aeolian dust: A synthesis of direct measurements of dust deposition. Chemical Geology, 267(1-2): 46-63.

Levy R, Hsu C. 2015. MODIS Atmosphere L2 Aerosol Product. NASA MODIS Adaptive Processing System. Goddard Space Flight Center, USA. [2017-11-25]. http://dx.doi.org/10.5067/MODIS/MOD04_L2.006.

Levy R C, Mattoo S, Munchak L A, et al. 2013. The Collection 6 MODIS aerosol products over land and ocean. Atmospheric Measurement Techniques, 6(11): 2989-3034.

Liu L, Mishchenko M I. 2008. Toward unified satellite climatology of aerosol properties: Direct comparisons of advanced level 2 aerosol products. Journal of Quantitative Spectroscopy and Radiative Transfer, 109(14): 2376-2385.

Lolli S, Madonna F, Rosoldi M, et al. 2018. Impact of varying lidar measurement and data processing techniques in evaluating cirrus cloud and aerosol direct radiative effects. Atmospheric Measurement Techniques, 11(3): 1639-1651.

Maiti D, Prasad B. 2016. Revegetation of fly ash: A review with emphasis on grass-legume plantation and bioaccumulation of 
metals. Applied Ecology and Environmental Research, 14(2): 185-212.

Martonchik J V, Diner D J, Kahn R, et al. 2004. Comparison of MISR and AERONET aerosol optical depths over desert sites. Geophysical Research Letters, 31(16), doi: 10.1029/2004gl019807.

Najafi M S, Khoshakhllagh F, Zamanzadeh S M, et al. 2014. Characteristics of TSP loads during the Middle East Springtime Dust Storm (MESDS) in western Iran. Arabian Journal of Geosciences, 7(12): 5367-5381.

Neff J C, Ballantyne A P, Farmer G L, et al. 2008. Increasing eolian dust deposition in the western United States linked to human activity. Nature Geoscience, 1(3): 189-195.

Ngan F, Stein A, Draxler R. 2015. Inline coupling of WRF-HYSPLIT: Model development and evaluation using tracer experiments. Journal of Applied Meteorology and Climatology, 54(6): 1162-1176.

Offer Z Y, Goossens D. 1994. The use of topographic scale models in predicting eolian dust erosion in hilly areas: Field verification of a wind tunnel experiment. Catena, 22(4): 249-263.

Opp C, Groll M, Aslanov I, et al. 2017. Aeolian dust deposition in the southern Aral Sea region (Uzbekistan): Ground-based monitoring results from the LUCA project. Quaternary International, 429: 86-99.

Prasad A K, Singh R P. 2007. Comparison of MISR-MODIS aerosol optical depth over the Indo-Gangetic basin during the winter and summer seasons (2000-2005). Remote Sensing of Environment, 107(1-2): 109-119.

Prospero J M, Nees R T, Uematsu M. 1987. Deposition rate of particulate and dissolved aluminum derived from Saharan dust in precipitation at Miami, Florida. Journal of Geophysical Research: Atmospheres, 92(D12): 14723-14731.

Qi Y L, Ge J M, Huang J P. 2013. Spatial and temporal distribution of MODIS and MISR aerosol optical depth over northern China and comparison with AERONET. Chinese Science Bulletin, 58(20): 2497-2506.

Quinn P K, Shaw G, Andrews E, et al. 2007. Arctic haze: Current trends and knowledge gaps. Tellus B, 59(1): 99-114.

Reheis M C, Kihl R. 1995. Dust deposition in southern Nevada and California, 1984-1989: Relations to climate, source area, and source lithology. Journal of Geophysical Research: Atmospheres, 100(D5): 8893-8918.

Remer L A, Tanré D, Kaufman Y J, et al. 2009. Algorithm for remote sensing of tropospheric aerosol from MODIS: Collection 005. National Aeronautics and Space Administration, 1490. http://citeseerx.ist.psu.edu/viewdoc/summary?doi=10.1.1.385.6530.

Rezaei M, Farajzadeh M, Mielonen T, et al. 2019. Analysis of spatio-temporal dust aerosol frequency over Iran based on satellite data. Atmospheric Pollution Research, 10(2): 508-519.

Rolph G, Stein A, Stunder B. 2017. Real-time environmental applications and display system: READY. Environmental Modelling \& Software, 95: 210-228.

Rubin J I, Reid J S, Hansen J A, et al. 2017. Assimilation of AERONET and MODIS AOT observations using variational and ensemble data assimilation methods and its impact on aerosol forecasting skill. Journal of Geophysical Research: Atmospheres, 122(9): 4967-4992.

Sabetghadam S, Khoshsima M, Alizadeh-Choobari O. 2018. Spatial and temporal variations of satellite-based aerosol optical depth over Iran in Southwest Asia: Identification of a regional aerosol hot spot. Atmospheric Pollution Research, 9(5): 849856.

Schaap M, Timmermans R M A, Koelemeijer R B A, et al. 2008. Evaluation of MODIS aerosol optical thickness over Europe using sun photometer observations. Atmospheric Environment, 42(9): 2187-2197.

Schaap M, Apituley A, Timmermans R, et al. 2009. Exploring the relation between aerosol optical depth and $\mathrm{PM}_{2.5}$ at Cabauw, the Netherlands. Atmospheric Chemistry and Physics, 9(3): 909-925.

Schepanski K, Heinold B, Tegen I. 2017. Harmattan, Saharan heat low, and West African monsoon circulation: Modulations on the Saharan dust outflow towards the North Atlantic. Atmospheric Chemistry and Physics, 17(17): 10223-10243.

Sokolik I N, Winker D M, Bergametti G, et al. 2001. Introduction to special section: Outstanding problems in quantifying the radiative impacts of mineral dust. Journal of Geophysical Research: Atmospheres, 106(D16): 18015-18027.

Song C H, Park M E, Lee K H, et al. 2008. An investigation into seasonal and regional aerosol characteristics in East Asia using model-predicted and remotely-sensed aerosol properties. Atmospheric Chemistry and Physics, 8(22): 6627-6654.

Sorooshian S, AghaKouchak A, Arkin P, et al. 2011. Advanced concepts on remote sensing of precipitation at multiple scales. Bulletin of the American Meteorological Society, 92(10): 1353-1357.

Stein A, Draxler R R, Rolph G D, et al. 2015. NOAA's HYSPLIT atmospheric transport and dispersion modeling system. Bulletin of the American Meteorological Society, 96(12): 2059-2077.

Stockli R, Jentoft M. 2013. Monthly Aerosol Optical Thickness (Aqua/MODIS). National Aeronautics and Space Administration, 30394. [2017-11-25]. https://svs.gsfc.nasa.gov/30394.

Stohl A. 2006. Characteristics of atmospheric transport into the Arctic troposphere. Journal of Geophysical Research: Atmospheres, 111(D11), doi: 10.1029/2005jd006888.

Taheri S H, Karimi K, Habibi N M, et al. 2015. Monitoring of dust storm and estimation of aerosol concentration in the Middle 
East using remotely sensed images. Arabian Journal of Geosciences, 8(4): 2095-2110.

Tegen I, Lacis A A. 1996. Modeling of particle size distribution and its influence on the radiative properties of mineral dust aerosol. Journal of Geophysical Research: Atmospheres, 101(D14): 19237-19244.

Wang H, Zhang L, Liu R, et al. 2011. Comparison and assessment of the MODIS C005 and C004 aerosol products over the China. Plateau Meteorology, 30(3): 772-783. (in Chinese)

Washington R, Todd M, Middleton N J, et al. 2003. Dust-storm source areas determined by the total ozone monitoring spectrometer and surface observations. Annals of the Association of American Geographers, 93(2): 297-313.

Wesely M L, Hicks B B. 2000. A review of the current status of knowledge on dry deposition. Atmospheric Environment, 34(12-14): 2261-2282.

Wu D L, Ackerman S A, Davies R, et al. 2009. Vertical distributions and relationships of cloud occurrence frequency as observed by MISR, AIRS, MODIS, OMI, CALIPSO, and CloudSat. Geophysical Research Letters, 36(9), doi: $10.1029 / 2009 \mathrm{gl} 1037464$.

Xiao N C, Shi T, Calder C A, et al. 2009. Spatial characteristics of the difference between MISR and MODIS aerosol optical depth retrievals over mainland Southeast Asia. Remote Sensing of Environment, 113(1): 1-9.

Yan H, Jiao M, Bi B, et al. 2006. Observation on sand-dust aerosol in center of Taklimakan Desert. Journal Desert Resesrch, 26(3): 389-393. (in Chinese)

Yasui M, Zhou J X, Liu L C, et al. 2005. Vertical profiles of aeolian dust in a desert atmosphere observed using lidar in Shapotou, China. Journal of the Meteorological Society of Japan, 83: 149-171.

Yu H, Dickinson R E, Chin M, et al. 2003. Annual cycle of global distributions of aerosol optical depth from integration of MODIS retrievals and GOCART model simulations. Journal of Geophysical Research: Atmospheres, 108(D3), doi: 10.1029/2002JD002717.

Yu X, Lü R, Kumar K R, et al. 2016. Dust aerosol properties and radiative forcing observed in spring during 2001-2014 over urban Beijing, China. Environmental Science and Pollution Research, 23(15): 15432-15442.

Zhang X, Gong S, Shen Z, et al. 2003. Characterization of soil dust aerosol in China and its transport and distribution during 2001 ACE-Asia: 1. Network observations. Journal of Geophysical Research: Atmospheres, 108(D9): 4261, doi: 10.1029/2002JD002632.

Ziyaee A, Karimi A, Hirmas D R, et al. 2018. Spatial and temporal variations of airborne dust fallout in Khorasan Razavi Province, northeastern Iran. Geoderma, 326: 42-55. 